NBER WORKING PAPER SERIES

\title{
ON THE IMPORTANCE OF MEASURING PAYOUT YIELD: IMPLICATIONS FOR EMPIRICAL ASSET PRICING
}

\author{
Jacob Boudoukh \\ Roni Michaely \\ Matthew Richardson \\ Michael Roberts \\ Working Paper 10651 \\ http://www.nber.org/papers/w10651
NATIONAL BUREAU OF ECONOMIC RESEARCH
1050 Massachusetts Avenue
Cambridge, MA 02138
August 2004

The authors thank Simon Benninga, Alon Brav, Eugene Fama, Ken French, Eli Ofek, Michael Weisbach, Robert Whitelaw and seminar participants at Goldman Sachs Asset Management and the December 2003 Finance and Accounting in Tel-Aviv Conference. We are responsible for all remaining errors. The views expressed herein are those of the author(s) and not necessarily those of the National Bureau of Economic Research.

(C)2004 by Jacob Boudoukh, Roni Michaely, Matthew Richardson, and Michael Roberts. All rights reserved. Short sections of text, not to exceed two paragraphs, may be quoted without explicit permission provided that full credit, including (C) notice, is given to the source. 
On the Importance of Measuring Payout Yield: Implications for Empirical Asset Pricing Jacob Boudoukh, Roni Michaely, Matthew Richardson, and Michael Roberts NBER Working Paper No. 10651

August 2004, Revised February 2006

JEL No. G1

\section{$\underline{\text { ABSTRACT }}$}

Previous research showed that the dividend price ratio process changed remarkably during the 1980 's and 1990's, but that the total payout ratio (dividends plus repurchases over price) changed very little. We investigate implications of this difference for asset pricing models. In particular, the widely documented decline in the predictive power of dividends for excess stock returns in time series regressions in recent data is vastly overstated. Statistically and economically significant predictability is found at both short and long horizons when total payout yield is used instead of dividend yield. We also provide evidence that total payout yield has information in the cross-section for expected stock returns exceeding that of dividend yield and that the high minus low payout yield portfolio is a priced factor. The evidence throughout is shown to be robust to the method of measuring total payouts.

Jacob L Boudoukh Leonard N. Stern School of Business

New York University

40 West 4th Street, 9-190

New York, NY 10012

and NBER

jboudoukh@stern.nyu.edu

Roni Michaely

Cornell University

rm34@cornell.edu

Matthew Richardson

Stern School of Business

New York University

44 West 4th Street, Suite 9-190

New York, NY 10012

and NBER

mrichar0@stern.nyu.edu

Michael Roberts

Duke University

mroberts@duke.edu 
While the irrelevance theorem of Miller and Modigliani (1961) implies that there is no reason to suspect that dividends play a role in determining equity price levels or equity returns, the theorem is silent on the usefulness of dividends in explaining these variables. It is then, perhaps, not surprising that there is a considerable literature exploiting the properties of dividends and dividend yields to better understand the fundamentals of asset pricing both in the time series and cross-section. Motivation for the former comes from variations of the Gordon growth model in which dividend yields can be written as the return minus the dividend's growth rate (see, for example, Fama and French (1988)), from consumption-based asset pricing models in which the firm's dividends covary with aggregate consumption (e.g., Lucas (1978) and Shiller (1981)), and so forth. Additional motivation comes from cross-sectional heterogeneity in tax, agency, and asymmetric information considerations (e.g., Litzenberger and Ramaswamy (1979), Jensen (1986), John and Williams (1985), Allen Bernardo and Welch (2000), and Grullon, Michaely and Swaminathan (2002)).

We propose that this underlying motivation really refers to distributed cash flow going to equity holders, be it dividends, or anything that substitutes for dividends such as repurchases. To the extent researchers find dividends to be a useful variable for empirically characterizing asset pricing models (e.g., Fama and French (1988), Campbell and Shiller (1988b), Hodrick (1992), Cochrane (1998), Charest (1979), and Benartzi, Michaely, and Thaler (1997)), two potentially important questions are how well do dividends proxy for total payout, and what are the implications of any mismeasurement? This issue is not vacuous as there is recent substantive evidence that repurchases have substituted for dividend payments over the last 15 to 20 years (see, for example, Fama and 
French (2001), Grullon and Michaely (2002), Dittmar and Dittmar (2002), and Brav, Graham, Harvey and Michaely (2005)). Thus, there is reason to believe that dividend and repurchase policies are not independent.

It then remains an empirical question whether these changes in payout policy are relevant to both time-series and cross sectional tests of asset pricing. Anecdotally, there is an emerging literature arguing that dividend yield has lost some of its allure as a key empirical variable in asset pricing (e.g., Stambaugh (1999), Valkanov (2001), Lettau and Ludvigson (2001), Cochrane (2001), and Goyal and Welch (2003)). This paper provides a comprehensive analysis of the impact of measuring dividends versus payouts on existing empirical asset pricing model results. We show that the loss of the predictive power of dividends is related to the definition of payouts in asset pricing tests.

Though the definition of total payout is conceptually straightforward, measuring this variable is a challenge. For example, identifying the fraction of repurchases meant to substitute for dividends is difficult, if not impossible, to discern. Since our focus here is on the asset pricing implications, we examine several measures of total payout, leaving the debate over which measure may be "more appropriate" to future research. Furthermore, we also consider a measure of total net payout yield, which accounts for cash flows from investors to the firm (e.g., seasoned equity offerings). We examine cash inflows since $e x$ ante there is the possibility that cash is raised to maintain dividends, in which case a correction to account for true economic dividends, the net inflows and outflows, needs to be examined (e.g., Allen and Michaely (2003)). As such, our analysis may be viewed more broadly as an examination of payout based measures in general. 
Figure 1 graphs aggregate series for common dividends, repurchases of common stocks, and sales of common stock by nonfinancial corporations in the merged CRSP/Compustat database from 1971 to $2003 .{ }^{1}$ Consistent with the literature, Figure 1 shows that payout yields are systematically underestimated if repurchases are ignored. The figure also shows that equity issuances represent a significant negative cash transfer to shareholders. While dividends comprised the majority of cash flows during the first part of the sample period, its relative share declined through the mid- to late-1980s. For example, the ratio of repurchases to total payouts (dividends plus repurchases) hovers between $5 \%$ and $15 \%$ through the early 1980 's, after which the ratio rises to near $50 \%$ by the end of the sample. ${ }^{2}$

We show that using dividends alone to describe payout is not just a bias per se (as illustrated in Figure 1), but it also has potential cross-sectional effects as the rank correlation between firms' dividend yield and firms' payout yield generally decreases over the sample. Moreover, the time series process for dividend yields is different than payout (and net payout) yield, carrying important implications for asset pricing in the context of the existing literature. Interestingly, the time series processes for dividend yields prior to the emergence of repurchases as a significant form of distributing cash and that of payout yields after repurchases became dominant look remarkably similar. This supports the paper's thesis that repurchases should be taken into account when relating yields to expected returns. $^{3}$

The omission of alternatives to dividends as a means of payout introduces a measurement error problem both in the time series and cross-section. While this measurement error is potentially an important issue from a theoretical perspective, the 
focus of the paper is on documenting the empirical importance of measuring total payouts (dividends plus repurchases) and total net payouts (dividends plus repurchases less equity issuances), or more succinctly payouts and net payouts, on asset pricing tests. In particular, this paper looks at time-series and cross-sectional regressions of asset returns on various measures of payout yields. The basic strategy is to first document the results using dividend yields, then show how the results change as we incorporate repurchases and, ultimately, issuances. We report several findings.

First, the evidence of stock return predictability in the time series is much stronger using payout (net payout) yield. For example, for our full sample period (1926-2003) the regression of returns on dividend yield at an annual frequency and horizon generates an $R^{2}$ of $5.5 \%$ and a coefficient of 0.116 with a $t$-statistic of 2.240 . The total payout yield regressions, depending on the measurement of repurchases, exhibit R-squares of $8.0 \%$ and $9.1 \%$, an increase of $45 \%$ and $65 \%$ respectively. The net payout yield regression exhibits an R-square of $26 \%$, an almost five-fold increase. Moreover, while the bias-adjusted (Stambaugh 1999) dividend yield coefficient is insignificant, those of the payout and net payout yields are strongly significant. In a horse race between dividend yield and (net) payout yield we see that any association between dividends and returns disappears, captured entirely by the other payout variable. Finally, using the out-of-sample predictability framework of Goyal and Welch (2004), we show that our payout measures exhibit positive and robust predictability in spite of model uncertainty due to repeated rolling estimation.

Insight into this improved predictability is found in the dynamic properties of the individual yield series. Structural break tests reveal instability in the dividend yield series 
around the time of the enactment of SEC rule 10b-18, which provides a legal safe harbor for firms repurchasing their shares in accordance with the rule's provisions. In contrast, no such instability is detected in the payout measures. Furthermore, regression results over the period 1926-1985 show that our payout yield coefficient is very similar to those found in the full sample regressions. Thus, this evidence in total suggest that explanations of dividend yield's apparent decline as a predictive variable based on arguments such as spurious statistics, learning, et cetera, may not be the dominant force behind the reduced predictive power of dividend yield. Rather, the result may simply be an outcome of using dividend yield instead of payout yield.

Second, we find that the payout yield measures have a stronger correlation with returns than dividend yield measures in the cross section. For example, the average monthly returns on low, medium, and high payout (net payout) yield portfolios are $1.28 \%$ (1.24\%), $1.40 \%$ (1.36\%), and 1.56\% (1.57\%), respectively. In contrast, similar dividend yield portfolios exhibit average monthly returns of $1.15 \%, 1.28 \%$ and $1.33 \%$, respectively. Thus, the cross-sectional relation between total payout yield and returns is more distinct than the relation between dividend yield and returns. This conclusion is reinforced by Fama-MacBeth regressions of returns on beta, size, book-to-market, and our yield variables. In these cross sectional-time series regressions, dividend yields show an insignificant association with returns, whereas our payout measures exhibit highly significant associations with returns. Interestingly, book to market is subsumed within payouts when we confine our attention to those firms that actually pay out cash via dividends. 
Moreover, while there is a consistent relation between average returns and payout yields in the context of Fama-French 3-factor model regressions, this is not the case for dividend yields. Most important, asset pricing restrictions of the Fama-French 3-factor model can be rejected for a cross-section of portfolios sorted by these factors and payout yield. However, when a payout yield factor is added to the mix we cannot reject the restrictions of the model but for one of the three sets of portfolios.

Finally, based on these previous results, we devise a simple, self-financed, trading strategy that goes long a portfolio of high yield stocks and short a portfolio of low yield stocks; rebalancing these holdings on an annual basis (Figure 3). The strategy based on net payout yield exhibits an average annual return of $4.44 \%$ compared with $3.36 \%$ for the payout portfolio, and $2.16 \%$ for the strategy based on dividend yield. These strategies result in portfolios with negative market betas and negative loading on the size factor, suggesting that these returns are not likely to be explained by standard risk measures.

This paper is organized as follows. In Section II, we describe the data, including definitions, sources, and statistical properties. In Section III, we investigate the time-series and cross-sectional implications of the measurement problem form an empirical viewpoint. Section IV concludes. 


\section{Payout Yields: Data and Implications}

\section{A. Data Description}

For the cross sectional analysis, we follow closely the sample selection and variable construction methods of Fama and French (1992, 1993). Nonfinancial firms in the intersection of the CRSP monthly return file and COMPUSTAT annual files form the core of our sample. We also require that each firm have a strictly positive value for book equity from COMPUSTAT for its fiscal year ending in calendar year $t-1$. All fiscal year-end accounting variables in year $t-1$ are merged with the monthly returns for July of year $t$ to June of year $t+1$, ensuring that the accounting information is known prior to the returns that they are used to explain.

The book-to-market ratio is defined as the sum of fiscal year-end book equity (Compustat item \#60) and balance sheet deferred taxes (Compustat item \#74), divided by the CRSP market capitalization in December of the corresponding year. Firm size is defined as the CRSP market capitalization as of June in year $t$. Thus, the book-to-market for the end of fiscal year $t-1$ and the firm size in June of year $t$ are merged with the returns from July of year $t$ to June of year $t+1$.

We compute "pre-ranking” beta estimates for each stock by first regressing monthly returns on the contemporaneous and lagged market return, measured by the CRSP valueweighted index, using 24-60 months of historical data (as available). The pre-ranking beta estimate is the sum of the regression coefficients on the two market returns and is meant to adjust for nonsynchronous trading (Dimson (1979)). These estimates are updated annually each July by re-estimating the regressions after incorporating the most recent 
return data. We note that the estimation of pre-ranking betas imposes the additional requirement of at least 24 months of historical returns data for inclusion in our tests of monthly returns.

To compute post-ranking betas, we begin by sorting stocks into size deciles each month using the Fama and French size breakpoints. ${ }^{4}$ Within each size decile we then sort stocks into ten portfolios based on their pre-ranking beta estimates. This procedure generates 100 size/pre-ranking beta portfolios for which we compute monthly equalweighted returns. We then regress each portfolio's time series of returns on the contemporaneous and lagged CRSP value-weighted return and sum the resulting parameter estimates to obtain the post-ranking beta estimates. The post-ranking betas are then assigned to each stock in the corresponding portfolio.

For the construction of our yield variables, we begin by defining the relevant cash flow measures. Dividends are defined as the total dollar amount of dividends declared on the common stock of the firm during the year (Compustat item \#21).

Repurchases are defined in two ways, highlighting the difficulty in measuring repurchases that substitute for dividends. The first measure captures all cash flows generated from any repurchase activity, and is defined as the total expenditure on the purchase of common and preferred stocks (Compustat item \#115) plus any reduction in the value of the net number of preferred stocks outstanding (Compustat item \#56). ${ }^{5}$ This data is available from the statement of cash flows for the period 1971-2003. The second measure of repurchases attempts to exclude those repurchases that may be earmarked for compensation or payment-in-kind (Fama and French (2001)). Such a situation can occur when firms repurchase shares in anticipation of employee stock option exercise activity. 
As such, our second measure of repurchases is defined by the change in treasury stock, adjusted for potential asynchronicity between the repurchase and option exercise. ${ }^{6}$

From a theoretical perspective, the distinction between these two alternatives is important, though not the focus of this paper. Rather, for our purposes, the relevant issue is which measure better captures the relation between payout and expected returns, and the extent to which repurchases substituted for dividends. There are several theoretical reasons why dividends and repurchases may be substitutes. First, from a tax perspective, firms may prefer to switch from dividend payments to repurchases, which are more tax effective. Second, in most agency (e.g. Jensen (1986)) and signaling models (e.g., Miller and Rock (1985)) dividends and repurchases play a similar role. Indeed empirically, Grullon and Michaely (2002) provide two important pieces of evidence that support the idea of a substitution effect between repurchases and dividends. First, they show that, conditional on Lintner's (1956) dividend model, the difference between actual and expected dividend payments is negatively correlated with a firm's repurchase activity. Second, the market reaction upon an announcement of a dividend decrease is much less negative for firms that are repurchasing shares. Though these results support the substitution hypothesis, they provide a noisy measure of the exact portion of repurchases that substitute for dividends, which we attempt to address by using more than one repurchase measure.

There are also several reasons why repurchases may be independent of a firm's dividend policy and, therefore, inappropriate as a substitute for dividends. For example, a firm might do one-off repurchases as a way of reducing agency conflicts within the firm (Jensen (1986)) or as a signal of the firm's being undervalued (Vermaelen (1984)). If 
dividend policy is not affected by such activities, then it is not clear that these repurchases will be helpful for our understanding of the risk-return relation that is the focus of this paper.

Our final cash flow measure is motivated by corporate finance theories, such as Miller and Modigliani (1961) and Miller and Rock (1985), in which there is no distinction between outflows (i.e., dividends and repurchases) and inflows (i.e., issuances). As such, we examine a measure of equity issuances defined as the sale of common and preferred stock (Compustat data item \#108) minus any increase in the value of the net number of preferred stocks outstanding (Compustat item \#56). This data is available from the statement of cash flows for the period 1971-2003.

With our cash flow measures, we construct five primary yield variables: dividend yield, payout yield (two measures), and net payout yield (two measures), each of which is normalized by the contemporaneous year-end market capitalization. Payout is defined as the sum of dividends and repurchases. Net payout is defined as the sum of dividends and repurchases minus issuances. Since we have two measures of repurchases, we have two corresponding measures of payout yield and net payout yield: a cash flow based measure and a treasury stock based measure. To ease the presentation and discussion that follows, we focus our attention on only the dividend yield, both payout yields, and the cash flow based net payout yield. Results using the treasury-stock based net payout yield generate qualitatively similar findings.

As with the book-to-market variable, all year-end $t$-1 yield variables are merged with monthly returns from July of year $t$ to June of year $t+1$. Additionally, to ensure consistency across analyses, we trim the upper and lower 0.5 percent of the book-to- 
market distribution, the upper 5 percent of the dividend yield and payout yield distributions, and upper and lower 2.5 percent of the net payout yield distribution, to mitigate the effect of outliers. ${ }^{7}$

Time series analysis combines the standard data from CRSP with repurchase data from COMPUSTAT. In particular, the dependent variable, excess return on the market, is the log difference in the total return on the CRSP value-weighted index minus a proxy for the riskless interest rate for the period 1926-2003. ${ }^{8}$ The dividend yield, total dividends over the past year divided by current price, is imputed directly from CRSP's return series by taking the log difference in cum- and ex-dividend returns. The repurchase yield is calculated separately by taking the total dollar repurchases during each year from Compustat and dividing by the corresponding year-end market capitalization. Our payout yield is the sum of dividend- and repurchase-yields. Our repurchase yield is only available beginning in 1971 (1984 for repurchase yield calculated from treasury stocks) and, as such, we assume that repurchases were zero prior to this date so that our dividend and payout yields match exactly prior to 1971 (1983). As Figure 1 shows, repurchases were of negligible size until the mid-1980s, so this lack of data is likely to have little effect on our results.

To calculate net payout yield we subtract the equity issuance yield, defined as the ratio of equity issuances to market capitalization, from the payout yield. ${ }^{9}$ While the assumption of a zero repurchase yield prior to 1971 may be reasonable, assuming a zero issuance yield is less so because equity issuances represent a significant fraction of cash flows even before this date. Thus, we examine an alternative definition of net payout. Motivated by Goyal and Welch (2005) and an early working paper version of Fama and French (2004) 
we compute the value of net (of repurchases) equity issuances as the monthly change in shares outstanding times the average share price. ${ }^{10}$ Annual numbers are obtained by summing over firms each year. The ratio of the annual aggregate net issuances to the corresponding year-end market capitalization is then subtracted from our dividend yield to obtain the net payout yield prior to 1971. The drawback of this measure is that it captures issuances not generating cash flows (e.g., acquisitions and stock grants). However, this definition enables us to measure net payout yield beginning as early as $1926 .{ }^{11}$

It is important to note that, for the results to follow, the tendency of the measurement error in either cash-flow-based repurchases or treasury-stock-based repurchases will be to dilute their impact. As a preview, we find strong support for the use of payout yield and net payout yield (as opposed to dividend yield alone) as a payout measure for understanding the risk-return relation.

\section{B. Preliminary Data Analysis and Observations}

As described earlier, Figure 1 presents the time series pattern of aggregate dividends, repurchases and issuances. Two observations are of particular interest. First, there is a gradual increase in repurchases over the latter half of the sample. This increase in repurchases is due primarily to the institution of SEC rule 10b-18 in 1982, which provides a safe harbor for firms conducting repurchases from stock price manipulation charges. ${ }^{12}$ The introduction of this rule provides a natural breakpoint for our analysis since the institutional change was, arguably, an exogenous event. Second, though the increase in repurchase activity is gradual, there is significant variation in the level of repurchases. 
This variation introduces noise in the comparison of dividend to payout yields, which may affect the relation, or lack thereof, between returns and yields.

[Insert Figure 1 here]

Thus, the question of whether Figure 1 has meaningful implications concerning asset pricing models depends on two conditions. The first condition is that the difference between dividend yield and payout yield - apparent from Figure 1 - should be associated with meaningful variation cross-sectionally and/or with shifts in the time-series process for the yield measures during the period in which repurchases substitute for dividends. Assuming that the above condition holds, the second condition is that the shift from dividend yield to payout yield has a significant economic affect on empirical asset pricing. We deal with the former condition in this section and the latter condition in the next section.

In terms of the impact of the mismeasurement of payout yields, it is natural to ask whether the cross-section of firms varies across dividend, repurchase and payout yields. This matters because it is standard practice to evaluate factors and returns via the sorting of stocks into portfolios. Panel A (B) of Figure 2 graphs the rank correlation between dividend yield and (net) payout yield and repurchase yield and (net) payout yield year by year. For brevity, we present only the results corresponding to the cash flow based measures, as the rank correlations using the treasury stock measure of repurchases produces similar results. Throughout the 1970's, the correlation of dividend yield with payout yield was close to one. This is not surprising, as the primary cash payout method was dividends. However, by the mid 1980's the correlation had dropped below 0.8 and, in 1997, it had dropped to under 0.7. In contrast, the correlation between repurchase yield 
and payout yield increased dramatically over the sample horizon. Remarkably, by the end of the sample period, ranking firms by repurchases was a more accurate assessment of payout yield ranks than using dividend yields. Panel B of Figure 2 presents similar evidence for net payout yield.

[Insert Figure 2 here]

The implication of these results is that asset pricing tests employing measures of cash distributions to shareholders are less likely to accurately capture economic effects if these studies ignore repurchases (and issuances). Thus, for those tests that are derived from theory (such as the consumption-based asset pricing models described earlier), it is clear that one needs to include the total cash paid to shareholders. However, one caveat is in order. From a statistical perspective, if our objective is to explain the change in the explanatory power of dividend yield since the beginning of the 1980s one could argue that only those cash flows that substitute for dividends should be included. It is not clear that the information content of share repurchase announcements is identical to that of dividend change announcements (e.g. Grullon and Michaely (2004)). Indeed, there is some evidence that repurchases have more explanatory power for expected returns than dividends (e.g., Lakonishok, Ikenberry and Vermaelen (1995) and Benartzi, Michaely and Thaler (1997)). Thus, if one takes the view that the variable of interest is the one that best explains variation in future returns (e.g., Fama and French $(1992,1993)$ ); it may be the portion of repurchases not substituting for dividends that has the explanatory power. A similar caveat holds when extending dividends to total net payout via the inclusion of equity issuance. In particular, we must bear in mind the evidence in Baker and Wurgler (2000) on the predictive power of the equity share of total debt and equity issuance. Our 
evidence differs significantly in that we examine equity issuance deflated by price (i.e., the net yield).

As important as the cross-sectional characteristics of dividend versus payout yields are the time-series features. By far the strongest evidence and greatest use in asset pricing models is the treatment of dividend yield as the primary source of fundamental movements in asset prices, either directly through cash flow distributions or via its impact on time-varying expected returns. This literature covers the excess volatility studies (e.g., Shiller (1981), Grossman and Shiller (1981), Marsh and Merton (1986), Kleidon (1986), Campbell and Shiller (1988a), Campbell (1991) and Cochrane (1991), among others), the predictability of stock returns (e.g., Hansen and Singleton (1983), Fama and French (1988, 1989), Ferson and Harvey (1991) and Hodrick (1992)), and the process for dividend yields and its implications for returns (e.g., Campbell and Shiller (1988b), Cochrane (1998), Ang and Bekaert (2001), Lettau and Ludvigson (2001), Fama and French (2002) and Lewellen (2003)).

Panel A of Table I provides a summary of the properties of the dividend, payout, and net payout yield time-series processes over the sample periods commonly examined in previous empirical studies. As documented by others, the time-series process for dividend yields is dramatically different in comparing the 1926-1985 to the 1926-2003 sample periods. In particular, the process is much more persistent over the longer period (see, e.g., Goyal and Welch (2003)). For example, the AR(1) parameter increases from 0.805 to 0.944 . This is a dramatic shift towards interpreting the dividend yield process as being nonstationary. This, in turn, casts doubt on the underlying economic intuition of stock return predictability. Table I presents Dickey-Fuller tests for nonstationarity using 
the autocorrelation coefficient (set up as an $\mathrm{AR}(1)$ regression with an intercept), i.e., the test statistic $(\hat{\rho}-1) / \hat{\sigma}_{\hat{\rho}}$. Using the Student-t distribution is inappropriate under the null of a unit root, so we use the critical values provided by Fuller (1996). For example, the $10 \%$ critical value is -2.57 . The shift in autocorrelation from 0.805 for the subsample to 0.944 in the full sample translates into a shift from a test statistic of -2.311 to -1.159 , a shift from borderline-rejection of the unit root null to being well within the confines of a unit root.

\section{[Insert Table I here]}

Panel A of Table I provides additional evidence that questions the above interpretation. If one treats the payout yield as the appropriate process to study, the shift in the process from the 1926-1985 sample to the 1926-2003 sample is much more marginal. In this case, the AR(1) coefficient increases from 0.809 to just 0.863 using cash-flowbased repurchases. Since treasury stock data is only available beginning in 1984, the dividend yield and payout yield using treasury-stock-based repurchases are identical from 1926-1984. Thus, we compare the total payout yield computed using treasury-stock-based repurchases for the full sample (1926-2003) with the dividend yield for the partial sample (1926-1984). When we do, we see the AR(1) coefficient rise from 0.802 to $0.906 .{ }^{13}$ The unit root test statistics are of much higher magnitude in the full sample, namely -2.309 and -1.724 using the two measures.

An alternative way to look at the time-series process for dividend yields and payout yields in the predictive regressions is to perform tests for a structural break. While in reality the shift (if any) is most likely gradual, we nevertheless choose 1985 because of its proximity to the enactment of SEC rule $10 \mathrm{~b}-18$, discussed above. ${ }^{14}$ We perform the test for the driving processes underlying the dividend and total payout processes, as well as the 
predictive regressions. Panel B of Table I shows the dividend process seems to experience a structural break. The F-statistic is 3.725, with a corresponding $p$-value of 0.029. The dividend yield predictive regression's F-statistic is 3.270, with a $p$-value of 0.044 . For both repurchase measures similar calculations for the total payout process and related predictive regression do not show any evidence of a structural break. These results provide an interpretation for our earlier analysis of Dickey-Fuller tests statistics for a unit root. In particular, to the extent there is a break in the dividend price ratio time series, its stationarity is, not surprisingly, jeopardized in the full sample, a result of the structural break. We may now interpret the test as a result of a structural break rather than the additional data providing true evidence against stationarity of the underlying series. The results for net payouts are mixed, in that the autoregression shows a structural break, however, the predictive regressions do not. When we discuss in the next section in detail the results of these predictive regressions, we find, perhaps surprisingly, that this has no adverse effect on the net payout measure to predict market returns.

While the actual impact of this result for asset returns will be studied empirically in the next section, this finding tends to support the existing literature that relies on stationarity of dividend yields. Consider models that include dividend price ratios in VAR frameworks and exploit their implications for long-horizon expected returns (e.g., Campbell and Shiller (1988) and Cochrane (1998)). If one uses total payout as aggregate distributions to shareholders, one will reach similar conclusions to this earlier literature with respect to volatility of returns and its decomposition into time-varying risk premiums versus cash flow risk. 
Aside from making stationarity assumptions about dividend yields in theoretical finance models, some economists argue that stationary systems are a natural outcome of the equilibrium process. In this context, the above results lend support to the idea that payout yields are a more appropriate measure of cash flow distributions (and the underlying economic fundamentals) than dividend yields, confirming previously mentioned evidence in Grullon and Michaely (2002) and Dittmar and Dittmar (2002), albeit from a different perspective. Although we do not investigate the implications of the changed process for dividend growth versus payout growth rates in this paper, the results in Table I should prove useful for current research that focuses on the properties of dividend growth rates (e.g., Ang and Bekaert (2001), Lettau and Ludvigson (2001), and Menzly, Santos and Veronesi (2003)) or for reevaluations of excess volatility studies (Shiller (1981), Kleidon (1986), and Larrain and Yogo (2005)).

\section{Empirical Results}

The thesis of this paper is that most theories underlying dividend yield's usefulness in predicting stock returns do not distinguish how cash is transferred between the firms and its shareholders. Therefore, from a theoretical perspective, since all cash flow distributions to shareholders may have fundamental information about asset pricing, researchers should be careful in using dividend yields alone. From an empirical perspective we showed in Section I that the estimated process is more "consistent" if we include repurchases and cash flow from equity issuance, rather than using dividends alone. Still the extent to which this mismeasurement affects the empirical results reported 
in the literature remains an open question, which we now address following the strategy of Section I. Specifically, we investigate the properties of the stock return/dividend yield relation and then extend the analysis to include payout and net payout yields. The analysis is performed both in the time-series and the cross-section.

\section{A. Time-Series Predictability Analysis}

By far the most important result in the literature on estimating time-varying expected returns is the predictive power of dividend yields. For example, Campbell, Lo and MacKinlay (1997) as well as Cochrane (2001), in their book chapters discussing predictability, give center stage to empirical results involving the dividend price ratio. This evidence has been looked at across asset classes, across industries, and across countries. While there is significant debate about dividend yields as predictors, especially at long horizons, part of its extra scrutiny is due to it being the most single-pointed variable. ${ }^{15}$ Goyal and Welch (2003), for example, provide a detailed and thorough analysis of various measures of dividend yields and argue that the predictive power has been overstated both in- and out-of-sample. In particular, they document predictability prior to 1990 but show that this disappears when including the last decade. After considering various explanations, they argue that the most likely one is that the relation was spurious.

As argued in the literature, the last 15 years have exhibited a dramatic shift in the breakdown between payout yields and dividend yields (see, e.g., Cochrane (2001, P.391) and Allen and Michaely (2003)). Panel A of Table II presents the results of aggregate time series regressions of the market excess return on the dividend, payout, and net payout yield. From 1926-1984 (i.e., the "Early Sample") the coefficient on dividend yield is 
0.296 with $t$-statistic and $R^{2}$ of 3.666 and $13 \%$, respectively. However, when the recent history is included, the coefficient and explained variation drop dramatically, to 0.116 with a corresponding $t$-statistic of 2.24 and $R^{2}$ of $5.5 \%$. While statistical significance is still present, its temporary disappearance in the late 90's brought researchers to conclude that predictability based on dividend yields disappears. A series of high returns coupled with low dividend yields early in the new millennium brought back statistical significance (see our $t$-statistic of 2.240), but the breakdown in explanatory power and coefficient are still a resounding puzzle to early predictability stories. Moreover, this significance, when appropriately adjusted for the well known estimation bias inherent in this setting (See Stambaugh (1999)), disappears in the full sample, but not in the early subsample.

[Insert Table II here]

In contrast to the results for dividend yields, when we use the payout yield as a predictor for the entire sample period the regression coefficients, $t$-statistics and $R^{2} \mathrm{~s}$ change only mildly, and statistical significance is not lost. This is consistent with our explanation that measurement error and omitted variables are the culprit to the decline in dividend yield predictability. Interestingly, this is true irrespective of whether we use cash-flow-based repurchases or treasury-stock-based repurchases to correct dividend yield. For the cash-flow (and treasury-stock) -based payoff yield measures the regression coefficient drops from $0.280(0.300)$ to 0.209 (0.172), the $t$-statistic remains highly significant at any reasonable level, dropping from 3.688 (3.396) to 3.741 (2.854), and the $R^{2}$ drops from $12.1 \%(13.5 \%)$ to $9.1 \%(8.0 \%)$.

Before we turn to the results for net payout yield, it is useful to note that the regressor we use is constructed somewhat differently. In particular, the net payout yield is not 
necessarily positive anymore due to the netting out of equity issuances (see Section II.A above), hence, we cannot use $\log ($ yield) as our regressor anymore. Since we want to deviate as little as possible from the literature in this respect we simply bound the net yield away from negativitiy by defining the regressor as $\log ($ net yield +0.1$)$. The results are qualitatively robust to the precise size of the adjustment factor ( 0.1 in our case) but larger adjustments further remove the comparability of our estimates with that of the existing literature. $^{16}$

The results for net payout yield are quite striking. While the regression coefficient we obtain is not comparable to the ones computed above for total payout and dividend yield, the $t$-statistic and $R^{2}$ are comparable. The $t$-statistic is 5.311, significant at any standard level. The $R^{2}$ is $26.2 \%$. This result is striking in light of the baseline level of predictability using dividends alone of 5.5\%, or even in light of the payout measures' explanatory power of $8.0 \%$ or $9.1 \% .^{17}$

There are two potential statistical objections to the evidence of predictability at short horizons, namely the small sample bias of the predictive estimator (e.g., Stambaugh (1986)) and the breakdown of typical asymptotics in small samples due to the presence of highly persistent regressors (e.g., Elliott and Stock (1994)). Because these statistical issues arise as a result of the properties of the predictive variable, it is possible that the different results for the dividend versus the payout measures may be due to these issues rather than fundamentals. It is important therefore to document the differential evidence with the appropriate corrections.

With respect to small sample bias, Stambaugh $(1986,1999)$ notes that the typically high persistence in regressors used in predictive regressions, coupled with the strong 
negative correlation between innovations to these regressors and asset returns themselves, create a bias in the predictive regression coefficient. When the bias is adjusted appropriately (e.g., downward), the regression coefficients typically are found to be insignificant. Lewellen (2004), more recently, pointed out that the autocorrelation of the regressor, when appropriately bounded below unity, would affect the Stambaugh bias by reducing the standard errors relative to those calculated while ignoring the constraint on the AR(1) coefficient of the regressor. In some cases (e.g., some periods and/or some regressors) this may have the effect of salvaging predictability.

Amihud and Hurvich (2004) suggest a simple method to implement the StambaughLewellen adjustment via OLS regressions ${ }^{18}$. Using their approach we compute biasadjusted beta coefficients and standard errors, which appear in Panel A of Table II. Since at an annual frequency the persistence in the regressor is lower and the correlation between returns and the innovations to the regressor is lower, the effect of the adjustment is smaller. Interestingly, due to the relatively high persistence in the dividend yield series (namely, 0.94) and the relatively high cross correlation between the regressor's AR(1) errors and returns (namely, -0.709) relative to the other regressors discussed next, the bias adjustment has sufficient bite to diminish the statistical significance of the dividend yield predictability obtained in standard OLS regression. In particular, while the OLS beta is 0.116 , the bias-adjusted beta is 0.072 , and while, as noted above, the OLS $t$-statistic is 2.240, it is 1.281 for the bias-adjusted beta. This lost significance is not the case, however, for all other regressors under consideration. In particular, the adjusted beta of the cashflow-based (treasury-stock-based) payout yield regressor is 0.167 (0.126) with a $t$-statistic of 2.192 (1.872). The statistical significance is not lost here because the adjustment 
necessary for the payout series is small. This is a result of the relatively low persistence of these regressors, coupled with the relatively weak correlation between the innovations to the regressors and returns.

With respect to possible size distortions of $t$-statistics due to near unit root properties of the regressor, Elliot and Stock (1994) derive an alternative asymptotic theory in which they explicitly model the regressor as a having a local-to-unit root. A number of finance papers have recently applied this theory to the question of stock return predictability (see, for example, Torous, Valkanov and Yan (2001), Jannson and Moreira (2003), Campbell and Yogo (2005), and Polk, Thompson, and Vuolteenaho (2003)). Under this alternative methodology, the researcher can construct Bonferroni-based tests that are robust to the persistence problem by directly incorporating Dickey-Fuller confidence intervals around the autoregressive parameter. In panel A of Table II, we present the 5\% confidence interval for the one sided Bonferroni Q-test using the test methodology and critical value in Campbell and Yogo (2005) ${ }^{19}$ For this relatively more conservative test we find that beta is bound away from zero for all three total payout variables, but not for dividend yield. The Bonferroni Q-test cannot reject that beta is zero for the dividend price ratio, with a lower confidence interval below zero, namely -0.007 . The gross payout measures are bound away from zero, with the lower point of the confidence interval being 0.035 for the cash flow based variable and 0.014 for the treasury stock one. The $5 \%$ lower tail of the total net payout variable is, as one would expect given its low persistence and high Rsquare, bound well away from zero, at 0.313 .

In conclusion, neither of the above statistical issues can explain the different predictability results using dividend yields versus the various payout measures. As an 
alternative comparison of the measures, we investigate their true predictive content from an economic perspective by turning to benchmarks recently set out in a series of papers by Goyal and Welch (2003, 2005). Goyal and Welch suggest an economically-motivated, intuitive benchmark for predictability, namely, out of sample performance. They compute the root-mean-squared-error differential (dRMSE) between two competing models (i) a myopic model, where expected returns are just the historical mean risk premium, and (ii) a predictability-based MSE, where expected returns are based on a rolling regression of available past data at any point in time. A reasonable economic benchmark for predictability to be interesting from an economic standpoint, they argue, is dRMSE $>0$.

In Table II we compute this measure with a rolling look-back window of 60 years and a forecast period starting in 1985. Consistent with Goyal and Welch, the dividend yield series does not provide sufficient predictive information to overcome statistical or modeling errors, hence, not only is its statistical validity questionable, but its economic relevance is doubtful. Interestingly, two out of the three alternative series that we examine do manage to beat the Goyal-Welch benchmark. The dRMSE is positive for all but the treasury-stock-based total payout variable. The cash-flow-based payout forecasts exhibit a dRMSE of $2.4 \%$, while that of the net payout is a remarkable $4.8 \%$ on a per annum basis.

The statistical significance of the dRMSE measure is examined in Goyal and Welch (2003) using asymptotic statistical theory developed by Diebold and Mariano. In some recent work, e.g., Clark and West (2005), authors have pointed out that statistical noise in the repeated estimation of predictive coefficients in the rolling regression framework can introduce a bias into the dRMSE measure. This is because in finite samples the RMSE 
under the null of no predictability is not expected to be zero, but, instead, negative. Motivated by small sample concerns, Goyal and Welch (2005) provide a bootstrapping analysis of the Diebold-Mariano dRMSE statistic and provide corresponding cutoff values. Similarly, we conduct a Monte Carlo simulation under the null of no predictability and obtain a simulation-based $p$-value for the dRMSE's given the relevant parameters. ${ }^{20}$ The dRMSEs of the cash flow based total payout series and that of the net payout series are not only positive, but also have impressive $p$-values of $8.2 \%$ and $2.2 \%$ respectively. That is, in simulations under the null of no predictability only $8.2 \%$ (2.2\%) of the times the dRMSE was greater than $2.4 \%$ (or $4.8 \%$ ).

Panel B of Table II provides a "horse race" between dividend yield and the various payout yield measures. Consistent with our main thesis, all three payout measures are highly significant, while dividend yield is insignificant in each case. For example, for the dividend yield and cash-flow-based total payout bivariate regression the $p$-value (not shown) on dividends is 0.790 while that of total payout is 0.007 . Comparing the $R^{2} \mathrm{~s}$ across univariate and bivariate regressions, we conclude that dividend yield's contribution to the regression is negligible in the presence of any of the other payout regressors. For example, the univariate $R^{2}$ for the cash-flows-based payout yield regressor is 9.2\% while in the bivariate case it is $9.8 \%$-- not a remarkable difference. This result, that dividends disappear when pitted against payout series, carries through to the other two regressions.

\section{B. Cross-Sectional Analysis}

The idea that dividends can be a useful measure for expected stock returns has early roots in finance (e.g., Dow (1920)). More recent research into the cross-sectional 
relation between dividend yields and returns is motivated not only by Dow's findings or the implication of the Gordon growth model, but by the presence of market imperfections. For example, Litzenberger and Ramaswamy (1979), among others, use tax motives to find a positive relation between expected returns and dividend yields in the context of a taxbased CAPM. Others studies (e.g., John and Williams, (1985), Allen Bernardo and Welch (2000), Grullon, Michaely and Swaminathan (2002)) turn to agency problems and information asymmetries in motivating a cross-sectional relation between equity returns and dividend yields. In this section, we explore (i) whether yields are useful measures for describing cross-sectional variation in expected returns, and (ii) whether the different yield measures (i.e., dividend versus (net) payout) lead to different conclusions. We close the section by comparing the performance of simple trading strategies based on our three yield measures.

Our first set of analysis examines the characteristics of stocks as a function of our different yield measures. Each year at the end of June, we form ten portfolios based on the ranked values of dividend yield, payout yield, and net payout yield from December of the previous year. Breakpoints for the decile portfolios are determined using only NYSE stocks with a non-zero yield. Stocks with zero yields comprise their own portfolio.

Table III presents the average monthly return, post-ranking beta, log firm size, log book-to-market, yield, and number of firms for each of ten positive yield portfolios, as well as for a portfolio of zero-yield stocks, for the period July 1984 to December 2003. With the exception of the first decile portfolio, there seems to be little cross-sectional return variation based on these portfolios, e.g., the lowest three deciles' mean monthly return is $1.15 \%$ monthly, the middle four deciles monthly return is $1.28 \%$, and the highest 
three is $1.33 \%$. This contrasts to the July 1963 to June 1984 period (not reported in the tables), in which these same portfolios increase sharply from the low deciles $(1.23 \%)$ to the high deciles (1.63\%). In both periods, the average beta decreases with the dividend yield while the average book-to-market ratio increases with dividend yields.

\section{[Insert Table III here]}

As far as the average return is concerned, the portfolios formed on (net) payout yield measures (Panels B through D) tell a different story. Most important, there is measurable cross-sectional variation in expected returns, the result being an almost monotonic relation between returns and payout yield. For the cash flow (treasury stock) based measure of payout yield, the lowest three deciles' mean is $1.28 \%(1.27 \%)$, the middle four is $1.40 \%(1.34 \%)$ and the highest three is $1.56 \%(1.51 \%)$. Note that finding higher payout yield portfolios having higher realized returns is consistent with the timeseries results documented in Section III.A. In that section, we documented higher returns during periods of high payout yields for the aggregate market. Like the dividend yield portfolios, the payout yield portfolios are negatively correlated with beta and positively correlated with book-to-market: High payout yield portfolios have lower betas and higher book-to-market ratios than low payout yield portfolios. Similarly, these inferences carry over to net payout yields, whose portfolio (low, medium, high) returns are $1.24 \%, 1.36 \%$, $1.57 \%$ and, are negatively correlated with beta and positively correlated with the book-tomarket ratio.

As is now standard in the literature, Table IV performs Fama-MacBeth monthly return regressions on post-ranking betas, book-to-market, size, and either dividend, payout, or net payout yield, over the period July 1984 to December 2003. Again, we focus 
on this later period corresponding to the period in which share repurchase activity is largely protected from legal action. Specifically, we run cross-sectional regressions every month in order to generate a time series of parameter estimates. As mentioned above, each year we trim the smallest and largest $0.5 \%$ of the observations for book-to-market, the largest $5 \%$ of the observations for dividend yield and payout yield, and the largest and smallest $2.5 \%$ of the observations for net payout yield. This trimming avoids giving extreme observations excessive weight in the regressions, although we also address this issue further by using a robust regression technique discussed below. Table IV presents the average value of each estimated parameter's time series, along with a corresponding standard deviation and $t$-statistic. Panel A presents the results for the entire sample and panel B presents the results when only the non-zero yield firms are included.

\section{[Insert Table IV here]}

For the OLS regressions on the entire sample, the standard results appear in the significantly negative coefficient on size and significantly positive coefficient on book-tomarket. The market beta coefficient is insignificant across all four specifications. More to the point of this paper, however, are the differences across our yield measures. Both the (cash-flow based) payout yield and net payout yield coefficients are positive and highly significant, whereas the dividend yield coefficient is insignificant. The coefficient on the $\log$ payout yield is 0.15 with a $t$-statistic of 2.24 , and the coefficient on net payout yield is 0.03 with a t-stat of 4.14 . The difference in coefficient magnitude is due to the inability to use the log transformation on the net payout yield because of negative values, thus preventing a direct comparison of the coefficients. ${ }^{21}$ The treasury stock based payout yield is also positive (0.08) and more than twice the magnitude of the dividend yield, but 
statistically insignificant. However, the important point is that relative to the dividend yield (coefficient of 0.03 with a t-stat of 0.38 ), payout yield and net payout yield show significantly stronger associations with stock returns.

One of the commonly cited problems in measuring the cross-section of returns is the extent to which the results are robust. In particular, Knez and Ready (1997) argue that robust estimation should be applied due to outliers and, indeed, find that the size effect reverses (becomes positive) when such a technique is applied. As such, we apply a similar method here by re-estimating the model using least absolute deviation (LAD) regression. Similar to Knez and Ready (1997), the standard size effect reverses sign. The book-tomarket effect remains positive and significant. Interestingly, the coefficient on log dividend yield is now significantly positive, though relatively less so than (net) payout yield.

Finally, in panel B we report OLS and LAD regression results for when the sample is restricted to only positive yield stocks. Interestingly, in the dividend yield specification of the OLS regression, the standard result no longer applies. That is, size and book-tomarket are not significantly related to returns. In the payout and net payout yield specifications, the size coefficient is still insignificant but the book-to-market coefficient is now significant. This change is due in large part to a larger sample of firms that pay dividends or repurchase shares compared to firms that only pay dividends. More to the point of this paper though, where the dividend yield is insignificant, the payout and net payout yields are significantly related to returns, but for the OLS estimate of the treasury stock based payout yield. The LAD estimates for the positive yield sub-sample show a similar pattern: the payout coefficients are positive and highly significant while the 
dividend yield appears relatively less important. This is consistent with the declining rank correlation between payout yields and dividend yields during the 1984-2003 period described above and in Figure 2.

Thus far, our results suggest that payout and net payout yields have explanatory power for cross-sectional variation of returns over and above the standard firm characteristics, and that the payouts' coefficients are robust to sample specification, as well as outliers. On the other hand, for most cases, during the period 1984-2003, the dividend yield coefficient is not able to explain cross-sectional variation in returns and is more sensitive to sample specifications. ${ }^{22}$

Given the evidence of cross-sectional covariation between stock returns and payout yield, we develop measures of dividend, payout, and net payout yields as potential factors. We begin by sorting firms into three dividend yield groups and three payout yield groups each year, based on their deciles discussed earlier. These low, medium, and high groups correspond to the bottom three, middle four, and top three deciles. We then construct nine portfolios from the intersection of the dividend and payout yield groups and compute value-weighted average returns for each portfolio. Our dividend yield factor is computed as the average return across the three high dividend yield groups minus the average return across the three low dividend groups. The (net) payout yield factor is constructed in a similar manner. This approach mirrors Fama and French’s (1993) method for forming the size and book-to-market factors and, as such, aids in purging the correlation between our yield factors. The result of this procedure is four monthly timeseries including: DYHML (corresponding to the dividend yield factor), PYCFHML (corresponding to the cash flow based payout yield factor), PYTSHML (corresponding to 
the treasury stock based payout yield factor), and NPYHML (corresponding to the net payout yield factor).

The analysis that we perform is standard and based on the original portfolio regressions performed by Fama and French (1993). We begin by merging monthly data for the risk-free return, excess market return, $S M B$ factor return, and $H M L$ factor return (all of which are obtained from Ken French's website) with our yield factors discussed above. These three time series, in addition to one of our yield factors, form the design matrix in our factor regressions. The dependent variables consist of monthly excess stock returns for three sets of 25 portfolios: beta/payout yield, size/payout yield, and book-tomarket/payout yield. ${ }^{23}$ To coincide with the existing evidence, these portfolios include zero yield stocks, though the construction of our factor returns do not. For the beta/payout yield portfolios, we sort NYSE stocks in June of each year $t$ into beta and (independently) payout yield quintiles. ${ }^{24}$ The 25 portfolios are then constructed from the intersection of the quintiles and a value-weighted monthly return is computed. We then regress monthly excess portfolio returns on an intercept, the excess market return, $S M B, H M L$ and either DYHML, PYCFHML, PYTSHML, or NPYHML. Panel A of Table V presents the estimated intercepts and yield coefficients, as well as the corresponding t-statistics, for the book-tomarket/yield portfolios. ${ }^{25}$

\section{[Insert Table V here]}

Before commenting on the results containing the yield factors, it is worthwhile documenting the findings for a conventional 3-factor model estimated on the three sets of portfolios described above: beta/payout yield, size/payout yield, and book-tomarket/payout yield. Panel B of Table V summarizes the test results. In terms of the 
number of significant alphas, we find 7, 4 and 8 out of 25, respectively. Of course, these alphas may be correlated, which calls for a joint test. We look at the standard Wald test that the alphas are all equal to zero. The Wald tests produce test statistics of 44.77, 82.93, and 46.54 , respectively, all of which are asymptotically distributed $\chi^{2}(25)$ and highly statistically significant. That these tests reject the joint hypothesis that all of the intercepts are zero is potentially important. While it is not the first rejection of the Fama-French model (see Davis, Fama and French (2000) and Cremers (2003), among others), it does suggest that portfolio returns sorted in some way on payout yield cannot be solely explained cross-sectionally by the Fama-French factors.

To this point there is some evidence that payout yield may be a factor in describing expected returns. Across all three cross-sections of portfolios sorted on payout yield and the other factors (i.e. beta, size, book-to-market), the alphas tend to be statistically indistinguishable from zero (see Panel A for the book-to-market/yield portfolios in Table $\mathrm{V}$ as a representative sample). For example, Panel B shows that relative to the three-factor model, for portfolios sorted on beta, size and book-to-market, the number of significant alphas substantially declines. For the dividend yield factor there are 2, 5 and 4, respectively, significant alphas compared to that for the cash flow based payout yield factor (2, 4 and 2), treasury stock based payout yield (1, 5, and 4), and net payout yield factor ( 0,6 and 0$)$. While the alphas are probably correlated, suggesting a joint hypothesis, the evidence presented here is suggestive of the importance of a yield factor albeit distinguishing somewhat less between dividend yield and payout yield relative to previous evidence. 
To complete the analysis, we perform a Wald test analogous to the one described above, the results of which are presented in panel B of Table V. We find a negligible difference when we include the dividend yield factor into the specification. However, when we replace the dividend yield with payout yield, the test-statistics fall uniformly across the portfolios for the treasury stock based payout measure and in all but the beta portfolio for the cash flow based payout measure. A further decline in test statistics is found when we include the net payout yield factor. In sum, excess returns are driven to zero, or generally closer in the case of size portfolios, as we progress from the FamaFrench 3-factor model to including the dividend yield, then payout yield, and, finally, net payout yield.

In terms of the coefficients on the payout yield, between one third and half of them are significant in the regressions, which suggests that they have useful information for describing cross-sectional variation above and beyond the usual factors. Moreover, the coefficients follow sensible patterns, such as a positive correlation between the yield factor coefficient and payout sorted portfolios. For each (net) payout measures, the estimated slope coefficients in the low yield portfolio are all negative while those in the highest yield portfolio are all positive. Thus, independent of the book-to-market portfolio, the coefficients tend to increase across the yield portfolios. This finding is consistent with the results of Table III on the relation between average returns and payout yields, and shows that it carries through even in the presence of the well-documented 3-factor model of Fama and French. Also consistent with our previous results, the strength of the association between the estimated yield coefficients and the yield portfolios appears to strengthen as we progress from dividend yield to payout yield to net payout yield. 
In concert, this cross-sectional evidence suggests that including repurchases have additional explanatory power for expected returns, and that these yields generally outperform dividend yields, which supports the measurement issue. The results of Tables 4 and 5 also suggest that investing in high yield stocks, especially when the yield measure includes repurchases, results in higher returns than investing in yield-neutral portfolios. These findings ultimately beg the question: How does the strategy of investing in high yield portfolios perform over time?

To illustrate the applicability of this analysis, we analyze the performance of various yield portfolios. We consider the popular trading strategy, Dogs of the Dow, and variations of that strategy based on our discussion. In its simplest form, this strategy amounts to buying high yield Dow-Jones-Index stocks (say a third). In Burton Malkiel's (2003) well-known book, A Random Walk Down Wall Street, he describes how this strategy historically outperformed the Dow Jones by 2-3\% per annum. Malkiel goes on to say, however, that once this strategy became popular, the returns disappeared - in his language "the dogs no longer hunt" (pp. 246). Our analysis, however, suggests an alternative explanation.

[Insert Table VI here]

Panel A of Table VI describes the monthly returns to buying portfolios of stocks formed on various yield measures during the period July 1984 to December 2003. Specifically, in June of each year, stocks are sorted into deciles based on their yield from the previous year. The High (Low) Yield portfolio consists of those stocks falling in the upper (lower) 30\% of the non-zero yield distribution. While the average monthly return of holding the market over this period is $1.12 \%$, the return corresponding to the top dividend 
yield portfolio is $1.35 \%$, a 20 basis point difference. However, when we consider the high (net) payout yield portfolios, we see average returns of $1.57 \%, 1.53 \%$, and $1.59 \%$ to the cash flow based payout yield, treasury stock based payout yield, and net payout yield, respectively. These returns effectively double the spread over the market return exhibited by the dividend yield portfolio. Turning to the risk characteristics of these portfolios, Panel A also presents their factor loadings, which reveal positive loadings on each of the factors, but statistically significant intercepts that range from 59 basis points per month for the dividend yield portfolio to 80 basis points per month for the net payout yield portfolio.

Panel B of Table VI presents a similar analysis for portfolios that simultaneously go long in the high yield portfolio and short in the low yield portfolio. Several observations are worth mentioning. First, the payout and the net payout yield have significantly higher returns than the dividend yield strategy. Second, this zero-finance strategy has a positive alpha which is the highest for the payout and net payout yield. Third, regardless of how the yield is being measured, this strategy has negative loadings on the market and size factors, and positive loading on the book-to-market factor. Finally, the payout yield and net payout yield portfolios exhibit substantial improvements in performance relative to the dividend yield portfolio. Figure 3 presents a graphical view of these portfolios performance over time and illustrates both the evolution of the yield factor and the viability of our findings as a trading strategy. We note that in most years the dividend, payout (cash-flow and treasury stock measures) and the net payout strategies were profitable (in 13 out of 19, 14 out of 19, 13 out of 18, and 12 out of 19 years, respectively).

[Insert Figure 3 here] 
Perhaps the most glaring result is the large negative return to the net payout yield portfolio in 2000, which stands in stark contrast to the other two portfolio returns. Closer examination of this result reveals that it is due primarily to a subset of firms that issued equity during 1998 (i.e., at just the right time) and garnered significantly large subsequent returns from July of 1999 to June of 2000. These firms fall predominantly in high-tech and bio-tech industries (SIC codes 7372, 7373, 7370, 2834, 2835, and 2836).

Overall, the results indicate that even after controlling for alternative risk-factors, these strategies appear to earn abnormal returns, as measured by the significantly positive intercepts. These returns are higher when repurchases and issuances are accounted for. At the same time, the analysis illustrates that while following this strategy is profitable, it is not an arbitrage, as evidenced by significant losses in a few years.

\section{Concluding Remarks and Future Research}

A reliable predictor of equity returns for much of the $20^{\text {th }}$ century, dividend yields recently lost some of their allure. In this paper, we argue that a more appropriate measure is total payout. We show that the apparent demise of dividend yields as a predictor is due more to mismeasurement than alternative explanations such as spurious correlation, learning, etc. The enactment of SEC rule 10b-18 in 1982 spawned an explosion in repurchase activity that had a profound affect on the manner in which firms distribute earnings to their shareholders. This shift in payout policy resulted in a magnification of an existing problem in measures of payout yields, namely, the exclusion of share repurchases. We show that once repurchases are accounted for, our measures of total 
payout yield show significant predictive ability in both the time series and cross-section of equity returns.

In particular, we present several key findings. First, the dividend yield process exhibits a structural break around the time of the SEC rule change, and a subsequent decline in its predictive ability once post-1984 data is included in the analysis. In contrast, payout yields show no significant change in their dynamic properties and, consequently, their predictive ability remains intact across various time periods. Additionally, the significant relation between returns and payout yield are robust to small sample considerations (e.g., Stambaugh (1999) and Lewellen (2003)). Finally, we show that payout yields exhibit significant out-of-sample predictability, using the framework of Goyal and Welch (2005), whereas dividend yields do not.

Second, much like the time series analysis, we provide evidence that payout yields contain information about the cross-section of future returns above and beyond that provided by dividend yields. Fama-MacBeth regressions reveal a statistically and economically significant relation between returns and payout yield, as opposed to the insignificant relation between returns and dividend yield. Further, factor regressions reveal that a payout yield factor constructed from a portfolio long stocks in the upper $30 \%$ of the yield distribution and short those in the bottom $30 \%$ of the yield distributions appears to be priced in the sense that asset pricing restrictions cannot be rejected in the presence of this payout factor, whereas they can be when only the traditional three-factors (Fama and French (1993)) are examined.

Since corporate theory does not distinguish between inflows and outflows (Miller and Modigliani (1961), Miller and Rock (1985), and Allen and Michaely (2003)) our 
analysis also enables us to address the more general issue of how cash flows between the firm and investors impact asset prices. We construct a measure of net payout yield incorporating both share repurchases and issuances. The results show an even stronger association between returns and net payout yields, in both the cross-section and time series, than that found with either dividend or payout yield.

The implications of this study, while straightforward, are broad. At a fundamental level, our results suggest that asset pricing frameworks disillusioned with the use of dividends as a fundamental variable can now consider total payouts as a more accurate measure. Further, new research that exploits the complex properties of dividend growth rates both at the aggregate and individual firm level should take care in their interpretation. Our results suggest a better approach would be to look at the growth rate for total payouts and proceed along those lines. 


\section{References}

Allen, Franklin, Antonio E. Bernardo, and Ivo Welch, 2000, A theory of dividends based on tax clienteles, Journal of Finance 55, 2499-2536.

Allen, Franklin, and Roni Michaely, 2003, Payout policy, in George Constantinides, Milton Harris, and Rene Stulz, eds.: Handbooks of Economics, North-Holland.

Amihud, Yakov, and C. Hurvich, 2004, Predictive regressions: A reduced-bias estimation method, Journal of financial and Quantitative Analysis 39, 813-841.

Amihud, Yakov, Clifford Hurvich, and Yi Wang, 2004, Hypothesis testing in predictive regressions, NYU Finance Department Working Paper 04-030.

Ang, Andrew and Geert Bekaert, 2001, Stock return predictability: Is it there?, Working Paper Columbia University.

Baker, Malcolm, and Jeffrey Wurgler, 2000, The equity share in new issues and aggregate stock returns, Journal of Finance 55, 2219-2257.

Benartzi, Shlomo, Roni Michaely, and Richard Thaler, 1997, Do changes in dividends signal the future or the past?, Journal of Finance 52, 1007-1043. 
Bens, Daniel A., Venky Nagar, and Douglas J. Skinner, 2002, Employee Stock Options, EPS Dilution, and Stock Repurchases, Working paper University of Michigan.

Black, Fischer, and Myron Scholes, 1974, The effects of dividend yield and dividend policy on common stock prices and returns, Journal of Financial Economics 1, 1-22.

Bossearts, Peter, and Pierre Hillion, 1999, Implementing statistical criteria to select return forecasting models: What do we learn?, Review of Financial Studies 12, 405-428.

Brav, Alon, John R. Graham, Campbell Harvey, and Roni Michaely, 2003, Payout policy in the $21^{\text {st }}$ century, forthcoming Journal of financial Economics.

Brennan, Michael, 1971, A note on dividend irrelevance and the Gordon valuation model, Journal of Finance 26, 1115-1122.

Campbell, John, 2000, Asset pricing at the millenium, Journal of Finance 55, 1515-1567.

Campbell, John, Andrew Lo, and A. Craig MacKinlay, 1997, The Econometrics of Financial Markets, Princeton University Press, Princeton, NJ.

Campbell, John, and Robert Shiller, 1988a, The dividend-price ratio and expectations of future dividends and discount factors, Review of Financial Studies 1, 195-228. 
Campbell, John, and Robert Shiller, 1988b, Stock prices, earnings and expected dividends, Journal of Finance 43, 661-676.

Campbell, John, and Motohiro Yogo, 2005, Efficient tests of stock return predictability, Working Paper Harvard University.

Charest, Guy, 1978, Dividend information, stock returns and market efficiency - II, Journal of Financial Economics 6, 297-330.

Clark, Todd E., and Kenneth D. West, 2005, Using out-of-sample mean squared prediction errors to test the martingale difference hypothesis, NBER Technical Working Paper 305.

Cochrane, John, 1991, Explaining the variance of price-dividend Ratios, Review of Financial Studies 5, 243-280.

Cochrane, John, 1998, “A frictionless model of U.S. inflation,” in Ben S. Bernanke and Julio J. Rotemberg, eds., NBER Macroeconomics Annual, Cambridge MA: MIT press, p. 323-384.

Cochrane, John, 2001, Asset Pricing, Princeton University Press, Princeton, NJ. 
Cremers, Martijn K., 2003, Multifactor efficiency and bayesian inference, Working Paper Yale University.

Daniel, Kent, and Sheridan Titman, 1997, Evidence on the characteristics of crosssectional variation in stock returns, Journal of Finance 52, 1-33.

Davis James, Fama Eugene F., and Kenneth R. French, 2000, Characteristics, covariances, and average returns: 1929 to 1997, Journal of Finance 55, 389-406.

Diebold, Francis X., and Roberto Mariano, 1995, Comparing predictive accuracy, Journal of Business and Economic Statistics 13, 253-263.

Dittmar, Amy, and Robert Dittmar, 2002, Stock repurchase waves: An explanation of the trends in aggregate corporate payout policy, Working Paper University of Michigan.

Dow, Charles H., 1920, Scientific stock speculation, The Magazine of Wall Street.

Elliott, Graham, and James H. Stock, 1994, Inference in time series regression when the order of integration of a regressor is unknown, Econometric Theory 10, 672-700.

Fama Eugene F., 1988, Market efficiency, long-term returns, and behavioral finance, Journal of Financial Economics 49, 283-306. 
Fama Eugene F., and Kenneth R. French, 1988, Dividend yields and expected stock returns, Journal of Financial Economics 22, 3-25.

Fama Eugene F., and Kenneth R. French, 1989, Business conditions and expected returns on stocks and bonds, Journal of Financial Economics 25, 23-49.

Fama Eugene F., and Kenneth R. French, 1992, The cross-section of expected stock returns, Journal of Finance 47, 427-465.

Fama Eugene F., and Kenneth R. French, 1993, Common risk factors in the returns on stocks and bonds, Journal of Financial Economics 33, 3-56.

Fama, Eugene F., and Kenneth R. French, 2001, Disappearing dividends: Changing firm characteristics or lower propensity to pay?, Journal of Financial Economics 60, 3-43.

Fuller, Wayne, 1996, Introduction to Statistical Time Series, Wiley.

Goetzmann, William, and Philippe Jorion, 1993, Testing the predictive power of dividend yields, Journal of Finance 48, 1083-1100.

Goyal, Amit, and Ivo Welch, 2003, Predicting the equity premium with dividend ratios, Management Science 49, 639-654. 
Goyal, Amit, and Ivo Welch, 2005, A comprehensive look at the empirical performance of equity premium prediction, Working Paper Emory University.

Grossman, Sanford, and Robert Shiller, 1981, The determinants of the variability of stock market prices, American Economic Review 71, 222-227.

Grinstein, Yanniv, and Roni Michaely, 2005, Institutional holdings and payout policy, Journal of Finance 60, 1389-1426.

Grullon, Gustavo, and Roni Michaely, 2002, Dividends, share repurchases and the substitution hypothesis, Journal of Finance 57, 1649-84.

Grullon, Gustavo, and Roni Michaely, 2004, The information content of share repurchases, Journal of Finance 59, 651-680.

Grullon, Gustavo, Roni Michaely, and Bhaskaran Swaminathan, 2002, Are dividend changes a sign of firm maturity?, The Journal of Business 75, 387-424.

Hansen, Lars, and Kenneth Singleton, 1983, Stochastic consumption, risk aversion, and the temporal behavior of asset returns, Journal of Political Economy 91, 249-265.

Harvey, Campbell, and Wayne Ferson, 1991, The variation of economic risk premiums, Journal of Political Economy 99, 285-315. 
Hodrick, Robert, 1992, Dividend yields and expected stock returns: Alternative procedures for inference and measurement, Review of Financial Studies 5, 357-386.

Jagannathan, Murali, Clifford P. Stephens, and Michael S. Weisbach, 2000, Financial flexibility and the choice between dividends and stock repurchases, Journal of Financial Economics 57, 355-384.

Jansson, Michael, and Marcelo J. Moreira, 2003, Optimal inference in regression models with nearly integrated regressors, Working Paper Harvard University.

Jensen, Michael. C., 1986, Agency costs of free cash flow, corporate finance, and takeovers, American Economic Review 76, 323-329.

John, Kose and John Williams, 1985, Dividends, dilution, and taxes: A signaling equilibrium, Journal of Finance 40, 1053-1070.

Kleidon, Allan W., 1986, "Variance bounds test and stock price valuation models, Journal of Political Economy 94, 953-1001.

Knez, Peter, and Mark Ready, 1997, On the robustness of size and book-to-market in cross-sectional regressions, Journal of Finance 52, 1355-1382. 
Lakonishok, Joseph, Ikenberry David and Theo Vermaelen, 1995, Market underreaction to open market repurchases, Journal of Financial Economics 39, 181-208.

Larrain, Borja, and Motohio Yogo, 2005, Does firm value move too much to be justified by subsequent changes in cash flow?, Working Paper University of Pennsylvania.

Lewellen, Jonathan, 2004, Predicting returns with financial ratios, Journal of Financial Economics 74, 209-235.

Lettau, Martin, and Sydney Ludvigson, 2002, Expected returns and expected dividend growth, Working Paper New York University.

Lintner, John, 1956, Distribution of incomes of corporations among dividends, retained earnings, and taxes, American Economic Review 46, 97-113.

Litzenberger, Robert, and Krishna Ramaswamy, 1979, The effects of personal taxes and dividends on capital asset prices: Theory and empirical evidence, Journal of Financial Economics 7, 163-195.

Lucas, Robert, 1978, Asset prices in an exchange economy, Econometrica 46, 1429-1445.

Malkiel, Burton, 2003, A Random Walk Down Wall Street, Norton. 
Marsh, Terry, and Robert Merton, 1986, Dividend variability and variance bounds test for the rationality of stock market prices, American Economic Review 76, 483-448.

Menzly, Lior, Tanos Santos, and Pietro Veronesi, 2004, Understanding predictability, Journal of Political Economy 112, 1-47.

Miller, Merton, and Franco Modigliani, 1961, Dividend policy, growth, and the valuation of shares, Journal of Business 34, 235-264.

Miller, Merton, and Kevin Rock, 1985, Dividend policy under asymmetric information, Journal of Finance 40, 1031-1051.

Miller, Merton, and Myron Scholes, 1982, Dividends and taxes: Empirical evidence, Journal of Political Economy 90, 1118-1141.

Nelson, Charles, and Myung J. Kim, 1993, "Predictable stock returns: The role of small sample bias”, Journal of Finance 48, 641-661.

Newey, Whitney, and Kenneth West, 1987, A simple positive semi-definite, heteroskedasticity and autocorrelation consistent covariance matrix, Econometrica 55, 703-708. 
Polk, Christopher, Samuel Thompson, and Tuomo Vuolteenaho, 2003, New forecasts of the equity premium, Working Paper Harvard University.

Robertson, Donald, and Stephen Wright, 2003, Dividends, total cashflows to shareholders and predictive return regressions, Working Paper University of Cambridge.

Shiller, Robert, 1981, The use of volatility measures in assessing market efficiency, Journal of Finance 36, 291-304.

Stambaugh, Robert F., 1986, Bias in regressions with lagged stochastic regressors, Working Paper University of Chicago.

Stambaugh, Robert F., 1999, Predictive regressions, Journal of Financial Economics 54, $375-421$.

Torous, Walter, Rossen Valkanov, and Shu Yan, 2001, On predicting stock returns with nearly integrated explanatory variables, Working Paper UCLA.

Vermaelen, Theo, 1984, Repurchase tender offers, signalling and managerial incentives, Journal of Financial and Quantitative Analysis 19, 163-181. 
${ }^{1}$ Using different measures of repurchases such as the change in treasury stocks (which account for stock options) restricts the sample to start in 1983. The results, however, exhibit a similar pattern.

${ }^{2}$ Using our measure of repurchases based on the change in treasury stock, this figure is around $30 \%$ towards the end of the sample period.

${ }^{3}$ Independent of this work, Robertson and Wright (2003) make a similar point about mismeasurement of dividend yields vis a vis repurchases and equity issuance. They find that by accounting for this mismeasurement stronger evidence of time series predictability is present, which is one of our findings as well.

${ }^{4}$ We thank Ken French for providing these data.

${ }^{5}$ This measure of repurchase activity is similar to the one used by Jagannathan, Stephens and Weisbach (2000). While we measure the repurchase activity only for common stocks, their measure uses the entire repurchase activity, which also includes preferred stocks. The difference, however, is minimal (see Grullon and Michaely (2002)). ${ }^{6}$ Specifically, our definition is motivated by that provided in the Appendix A.4 of Fama and French (2001), which defines repurchases as the change in the firm’s Treasury Stock (Compustat item \#226) or as the difference between repurchases and issuances from the statement of cash flows when the retirement method is used (see Fama and French (2001) for further details). We only include positive changes in the treasury stock (i.e., repurchases). We modify their measure by then adding to the year $t$ measure, any negative change that occurs in the subsequent year, $t+1$. Treasury stock data is available from 1982 to 2003, so that our change measure is available beginning in 1983. 
${ }^{7}$ Specifically, we trim the yield distributions based solely on positive yields in the case of dividend and payout yields, and non-zero yields in the case of net payout yields since many yields are zero.

${ }^{8}$ Due to data availability for our sample period we follow Goyal and Welch (2003) in using the three month rate instead of the one year rate. This should have no material effect on the results.

${ }^{9}$ The denominators of these ratios (dividend, repurchase, issuance) differ because of slight variations in data availability across the various yield measures. However, when we restrict attention to the subset of firms for which all yield variables have non-missing data (i.e., the denominator is the same), our results are unaffected.

${ }^{10}$ Specifically, we define net equity issued for firm $i$ in month $t$ from the CRSP monthly tapes as:

$$
\left(\text { shrout }_{t} \times \text { cfacshr }_{t}-\text { shrout }_{t-1} c f a c s h r_{t-1}\right) \times\left(\operatorname{prc}_{t} / \operatorname{cfacpr}_{t}+\operatorname{prc}_{t-1} / \operatorname{cfacpr}_{t-1}\right) / 2,
$$

where shrout is the number of shares outstanding, cfacshr is the cumulative factor to adjust shares, $c f a c p r$ is the cumulative factor to adjust price, and $\operatorname{prc}$ is the month-end share price. Net repurchases are obtained by negating this measure.

${ }^{11}$ We also examine two alternative measures of net equity issuance motivated by Goyal and Welch (2005), based on the net expansion in market capitalization. The first measure uses monthly, firm-level data to compute:

$$
\operatorname{Mcap}_{i t}-\operatorname{Mcap}_{i t-1}\left(1+\operatorname{RETX}_{i t}\right) \text {, }
$$

where Mcap is the end-of-period market capitalization and RETX is the price appreciation from $t-1$ to $t$ for firm $i$. The primary difference between this measure and the one based on 
the change in shares outstanding relates to the assumed price at which the net issuing activity occurs (e.g., average price versus month-end price, rights offerings, exchanges and reorganizations). The second measure uses aggregate market data, and replaces RETX with VWRETX, the value weighted price appreciation of the market. This aggregate measure captures net issuances due to firm entry (e.g., IPOs) and firm exit (e.g., bankruptcies and buyouts). However, all measures produce qualitatively similar results and as such these alternatives are not presented.

${ }^{12}$ See Grullon and Michaely (2002) for a detailed analysis on the impact of Rule 10b-18 on firms’ open market repurchase activity.

${ }^{13}$ Note that, due to very few aggregate repurchases relative to aggregate dividends prior to 1985, the processes are quite similar.

${ }^{14}$ The Chow test for structural break calls for the estimation of the model over the entire sample and the two subsamples. We obtain a sum of squared residuals for the full sample (RSS), for the early, pre-1985 subsample $\left(R S S_{E}\right)$, and for the late, post 1985, subsample $\left(R S S_{L}\right)$. Intuitively, a large difference between $R S S$ and the sum $R S S_{E}+R S S_{L}$ signifies a structural break. Specifically, the test statistic is

$$
F=\frac{\left[R S S-\left(R S S_{E}+R S S_{L}\right)\right] / k}{\left(R S S_{E}+R S S_{L}\right) /(n-2 k)} \sim F(k, n-2 k)
$$

where $n$ is the number of observations and $k$ is the number of regressors.

${ }^{15}$ For skeptical views, see Goetzmann and Jorion (1993), Nelson and Kim (1993), Stambaugh (1999), Bossaerts and Hillion (1999), Valkanov (2001) and Goyal and Welch (2003). 
${ }^{16}$ We have rerun both the time series and cross-sectional analysis (Fama-MacBeth regressions) defining the regressor as $\log ($ net yield +1.01$)$. The statistical significance is unaffected.

${ }^{17}$ Robertson and Wright (2003) reach similar conclusions with respect to the measurement of dividend yields versus payout yields. Their results are reassuring since they use a different econometric specification (cointegrating VAR framework rather than predictive regressions), different data sources (e.g., Federal Reserve/Bureau of Economic Analysis) and alternative definition for payouts. They do find, though, that the payout process is less persistent and that the cointegration restrictions implied by predictive regressions are not rejected with payouts but is rejected with dividend yields.

${ }^{18}$ For a summary of their method and related literature see also Amihud, Hurvich and Wang (2004).

${ }^{19}$ We would like to thank Motohiro Yogo for the use of his Gauss code. ${ }^{20}$ In particular, we simulate 78 observations of the dependent and independent variables. We simulate the independent variable based on its estimated AR(1) coefficients, drawing the first observation from the unconditional distribution. We simulate returns based on their sample mean and standard deviation. We also preserve the AR(1) innovations and returns' cross correlation. We repeat the simulation 10,000 times, using random normals. ${ }^{21}$ We choose not to offset the net payout yield, as done in the time series analysis, because many firms have substantially (greater than 10\%) negative net payout yields.

${ }^{22}$ We rerun the analysis reported in Table IV for January and non-January months separately. For the non-January months, our results are largely unaffected. Specifically, 
dividend yields are positive and either insignificant or marginally significant (depending on whether we examine the positive subsample or the entire sample). The (net) payout yields are all positive and highly significant. For January months, all of the yields are largely insignificant, though most estimates are negative.

${ }^{23}$ We use the cash flow based payout yield measure to form the portfolios.

${ }^{24}$ Size and book-to-market quintiles are formed using the breakpoints downloaded from Ken French's website and the corresponding sets of portfolios are formed in the same manner as the beta/total payout yield portfolios.

${ }^{25}$ For expositional purposes related to Table length, Panel A of Table V does not report the results related to beta and size portfolios. 


\section{Figure 1}

\section{Aggregate Cash Flows Received by Corporate Shareholders}

The sample consists of all nonfinancial firms in the intersection of CRSP and Compustat with data for dividends paid to common shareholders, repurchase of common stock, and sale of common stock. The figure presents the aggregate cash flows to shareholders. The height of the white bars represent a negative flow of funds from shareholders to corporations in the form of issuances of common stock. The height of the grey bars represent a positive flow of funds to shareholders from corporations in the form of common dividends. The height of the black bars represent a positive flow of funds to shareholders from corporations in the form of common share repurchases. All dollar figures are in billions and inflation adjusted to 2000 dollars using the all-urban CPI.

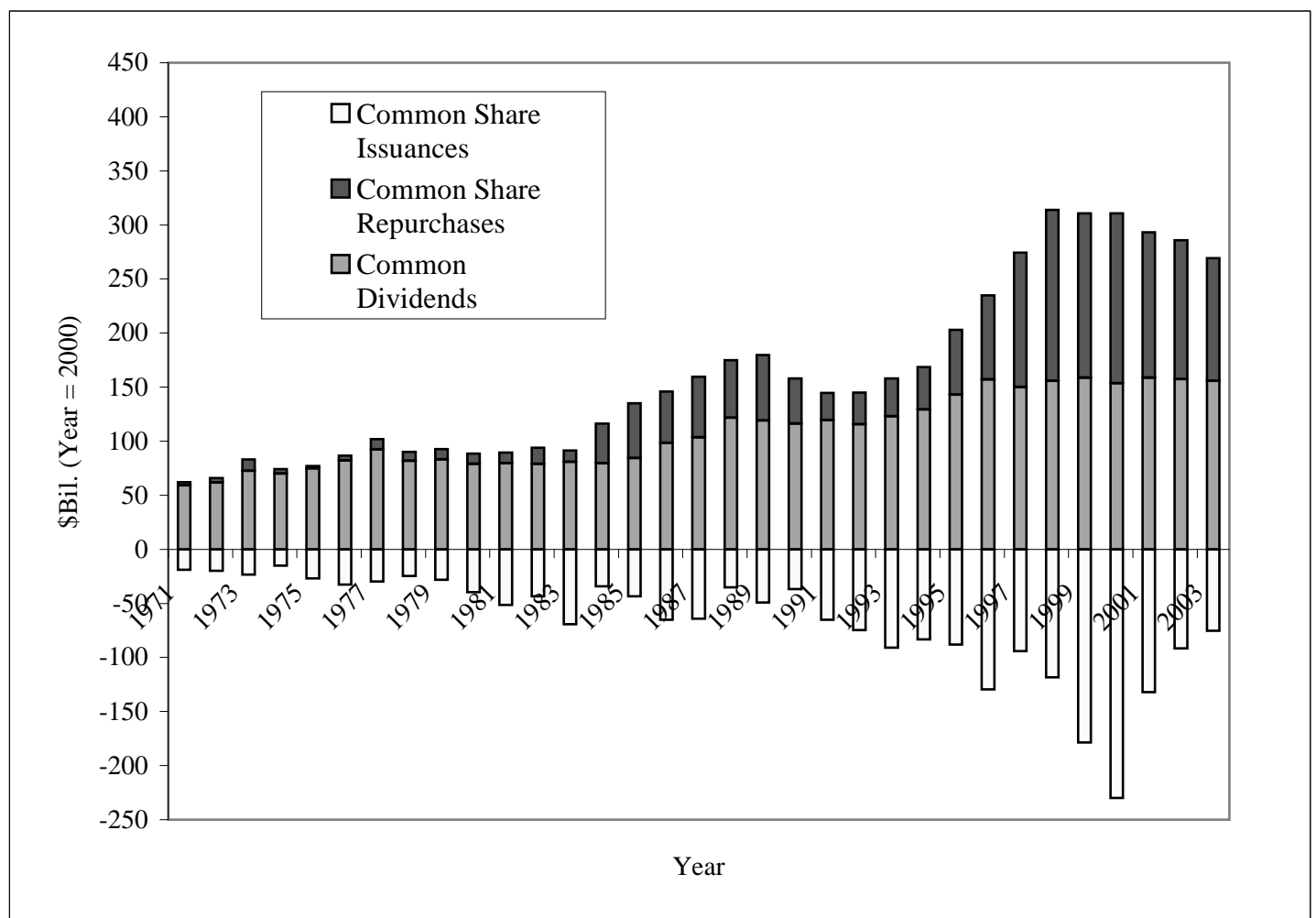




\section{Figure 2}

\section{Rank Correlations}

The sample consists of all nonfinancial firms in the intersection of CRSP and Compustat with data for market capitalization, dividends paid to common shareholders, repurchase of common stock, and sale of common stock. We also require that firms have at least two years worth of historical return data available on CRSP. Payout is the sum of dividends and repurchases. Net Payout is the sum of dividends and repurchases less issuances. All yields are computed by dividing the relevant variable by contemporaneous year-end market capitalization. Panel A presents two series of annual rank correlations for dividend yield and repurchase yield with payout yield. Panel B presents two series of annual rank correlations for dividend yield and repurchase yield with net payout yield.

Panel A: Annual Rank Correlation Between Dividend/Repurchase Yield and Payout Yield

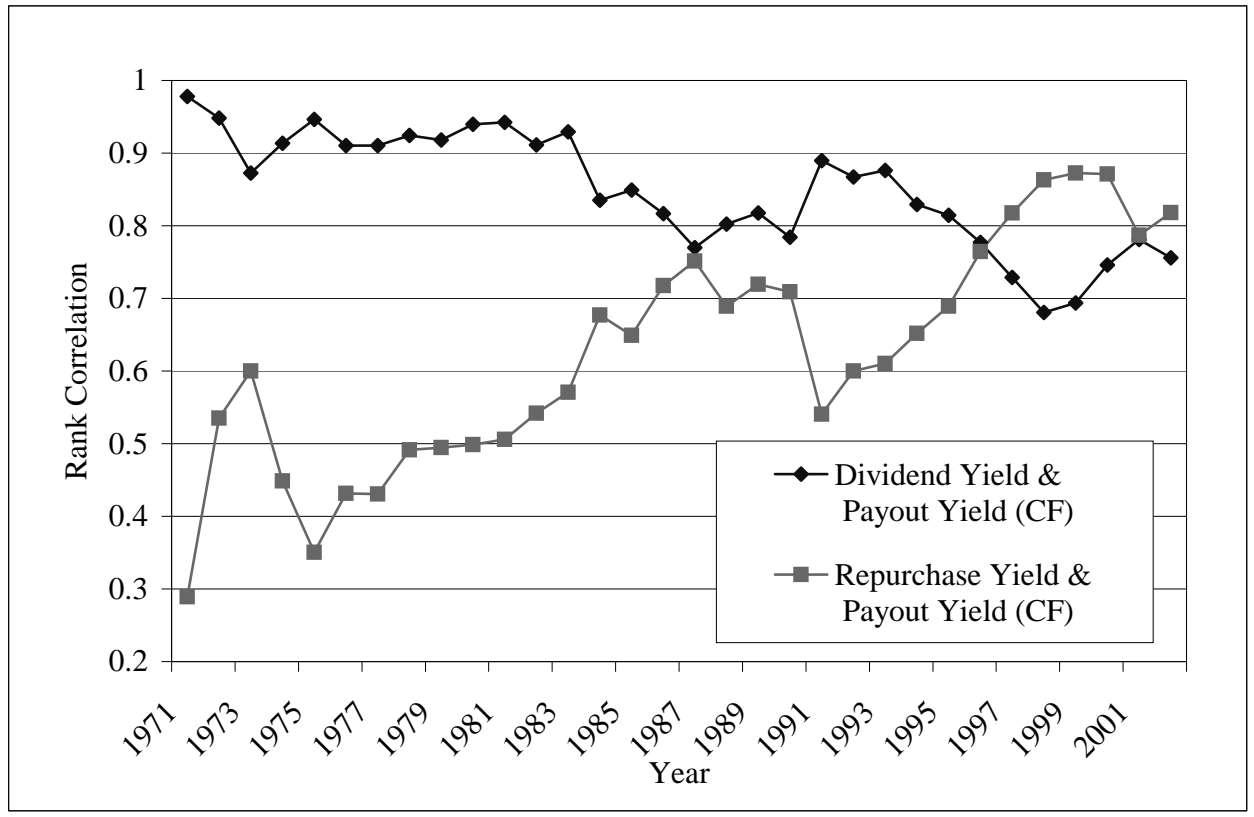


Panel B: Annual Rank Correlation Between Dividend/Repurchase Yield and Net Payout Yield

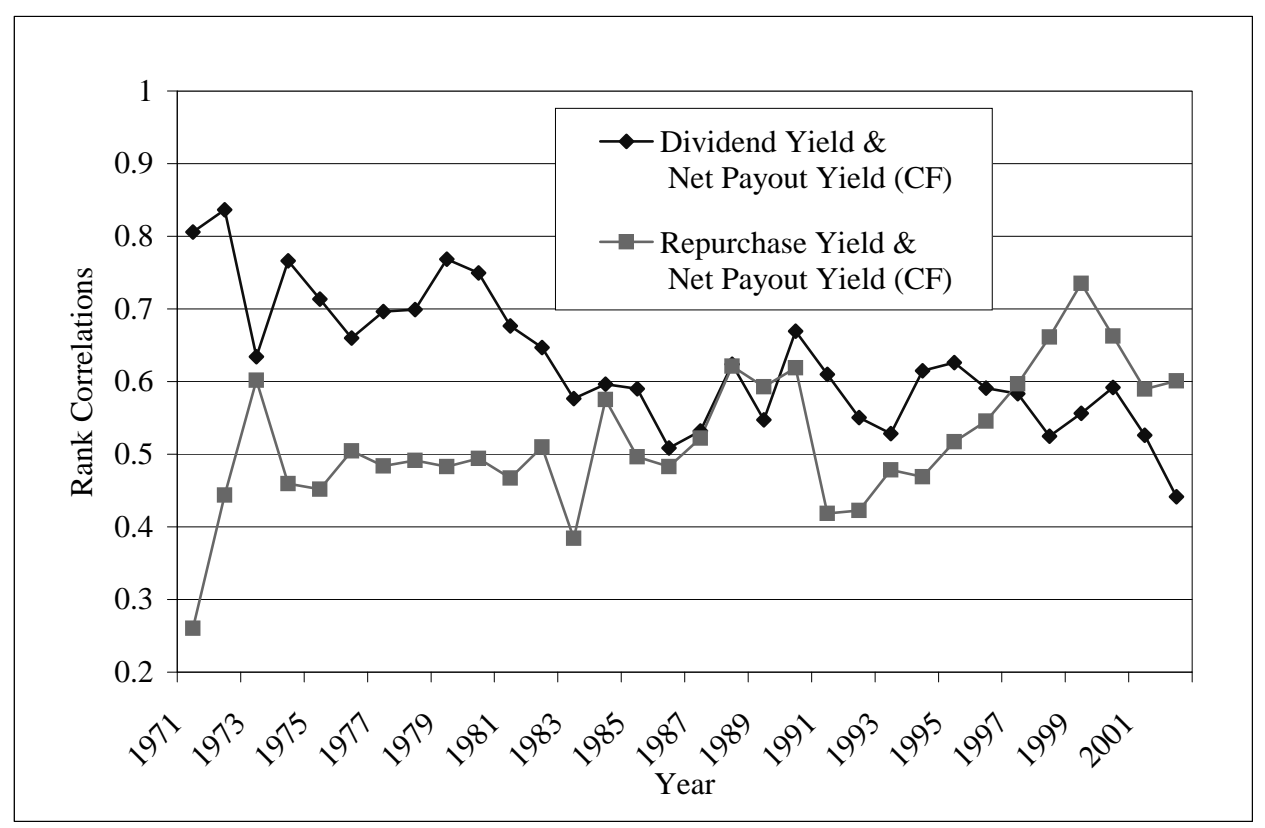




\section{Figure 3}

\section{Annual Returns for Yield Factors}

At the end of June of each year $t$, ten portfolios are formed on the basis of ranked values of dividend yield, payout yield and net payout yield. The dividend (payout) [net payout] yield is the ratio of common dividends (dividends plus common share repurchases) [dividends plus repurchases minus common share issuances] in year $t$ to year-end market capitalization. All stocks containing nonmissing data for the ratio of book-to-market equity, common share dividends, common share repurchases, and common equity sales, and at least two years worth of historical return data are then allocated to the yield portfolios using NYSE breakpoints based on positive yields (non-zero yields in the case of net payout). Each portfolio's monthly equal-weighted return for July of year $t$ to June of year $t+1$ is calculated, after which the portfolios are reformed. The figure shows annual returns to three portfolios, each of which represents a long position in stocks falling in the top $30 \%$ of the yield distribution and a short position in stocks falling in the bottom $30 \%$ of the yield distribution. Returns are computed by compounding monthly returns from July of year $t-1$ to June of year $t$. The dividend yield portfolio is denoted DYHML. The cash flow based payout yield portfolio is denoted PYCFHML. The treasury stock based payout yield portfolio is denoted PYTSHML (this series begins in 1986). The net payout yield portfolio is denoted NPYHML.

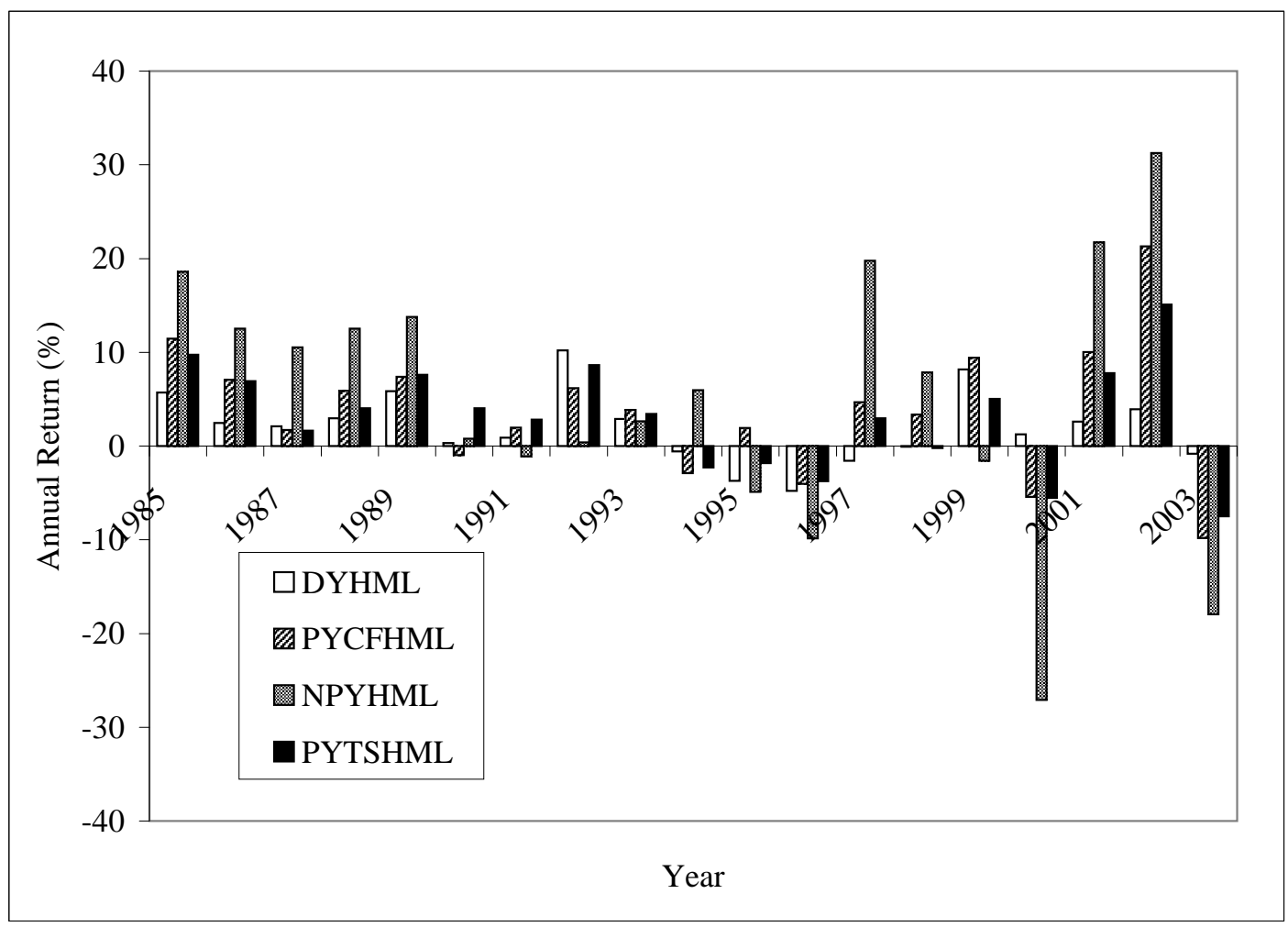




\section{Table I}

\section{Aggregate Time Series Summary Statistics}

The sample consists of all nonfinancial firms in the intersection of CRSP and Compustat with data for dividends paid to common shareholders, repurchase of common stock, and sale of common stock. Excess market return is the difference in the CRSP value-weighted total return (including dividends) and the return on a three-month Treasury bill. The Dividend yield is computed as the difference in the cum- and ex-dividend returns to the CRSP value-weighted index. The Payout Yield is the sum of dividend yield and repurchase yield, defined as the ratio of common share repurchases to year-end market capitalization. We measure repurchases in two ways using the statement of cash flows (data from 1971) and the change in the treasury stock (data from 1983). Because repurchases were negligible prior to and just after the passing of SEC Rule 10b-18 in 1982, we assume that repurchases are zero before the availability of each measure. The Net Payout Yield is the sum of dividend yield and repurchase yield (using the statement of cash flows measure) less the issuance yield, defined as the ratio of common share issuances to year-end market capitalization. Since repurchase and issuance data from the statement of cash flows begin in 1971, we use the monthly change in shares outstanding from the CRSP monthly stock file to capture net equity issuances prior to 1971. In particular, net equity issuance for month $t$ is the product of the split-adjusted growth in shares and the average of the split adjusted stock-price at the beginning and end of the month. All variables are in logs ( 0.1 is added to net payout yield to adjust negative yields). Panel A presents summary statistics on the aggregate time series. SD is the standard deviation. SE is the standard error. $\rho$ is the first-order autocorrelation coefficient. Statistic presents test-statistic values for hypothesis tests of the autocorrelation coefficients. For the excess market return, the null hypothesis is that $\rho=0$ and the test statistic, $(N-2)^{1 / 2}\left[\hat{\rho} /\left(1-\hat{\rho}^{2}\right)^{1 / 2}\right]$, is asymptotically standard normal under the null. For the yields, the null hypothesis is that $\rho=1$ and the test-statistic, $(\hat{\rho}-1) / \hat{\sigma}_{\rho}$, has a distribution under the null that is tabulated in Fuller (1996). Panel B presents results of Chow tests for a structural break in the dividend (payout and net payout) yield process and predictive regression. The test-statistic is:

$$
F=\frac{\left[R S S-\left(R S S_{E}+R S S_{L}\right)\right] / k}{\left(R S S_{E}+R S S_{L}\right) /(n-2 k)}
$$

where $R S S$ is the residual sum of squares for the full sample, $R S S_{E}$ is the residual sum of squares for the pre-1984 sample, $R S S_{L}$ is the residual sum of squares for the post-1983 period, $n$ is the number of observations, and $k$ is the number of regressors. $F$ is distributed $F(k, 2 n-k)$. 
Panel A: Summary Statistics

\begin{tabular}{|c|c|c|c|c|c|}
\hline & $\begin{array}{c}\log (\text { Excess } \\
\text { Market Return })\end{array}$ & $\begin{array}{l}\text { Log }(\text { Dividend } \\
\text { Yield })\end{array}$ & $\begin{array}{l}\text { Log(Payout } \\
(\mathrm{CF}) \text { Yield })\end{array}$ & $\begin{array}{l}\text { Log(Payout } \\
(\mathrm{TS}) \text { Yield) }\end{array}$ & $\begin{array}{c}\log (0.1+\text { Net Payout } \\
\text { Yield })\end{array}$ \\
\hline Mean & 0.058 & -3.272 & -3.149 & -3.210 & -2.042 \\
\hline $\mathrm{SD}$ & 0.200 & 0.411 & 0.292 & 0.334 & 0.135 \\
\hline \multicolumn{6}{|c|}{ Full Sample (1926-2003) Autocorrelations } \\
\hline$\rho$ & 0.089 & 0.944 & 0.863 & 0.906 & 0.659 \\
\hline $\mathrm{SE}$ & 0.143 & 0.048 & 0.059 & 0.055 & 0.157 \\
\hline Statistic & 0.621 & -1.159 & -2.309 & -1.724 & -2.167 \\
\hline \multicolumn{6}{|c|}{ Partial Sample (1926-1984) Autocorrelations } \\
\hline$\rho$ & 0.104 & 0.805 & 0.809 & 0.802 & 0.637 \\
\hline $\mathrm{SE}$ & 0.158 & 0.084 & 0.079 & 0.083 & 0.177 \\
\hline Statistic & 0.655 & -2.311 & -2.413 & -2.377 & -2.047 \\
\hline
\end{tabular}

Panel B: Structural Break Tests

\begin{tabular}{lcccc}
\hline AR $(1)$ & $\begin{array}{c}\log (\text { Dividend } \\
\text { Yield })\end{array}$ & $\begin{array}{c}\log (\text { Payout } \\
(\mathrm{CF}) \text { Yield })\end{array}$ & $\begin{array}{c}\log (\text { Payout } \\
(\mathrm{TS}) \text { Yield })\end{array}$ & $\begin{array}{c}\log (0.1+\text { Net Payout } \\
\text { Yield }\end{array}$ \\
\hline Statistic & 3.725 & 1.862 & 3.034 & 0.474 \\
P-Value & 0.029 & 0.163 & 0.054 & 0.625 \\
\hline Predictive & & & & 0.488 \\
\hline Statistic & 3.270 & 0.982 & 2.113 & 0.616 \\
P-Value & 0.044 & 0.380 & 0.128 & \\
\hline
\end{tabular}




\section{Table II}

\section{Return Predictability}

The sample consists of all nonfinancial firms in the intersection of CRSP and Compustat with data for dividends paid to common shareholders, repurchase of common stock, and sale of common stock. Excess market return is the difference in the CRSP value-weighted total return (including dividends) and the return on a three-month Treasury bill. The Dividend yield is computed as the difference in the cum- and ex-dividend returns to the CRSP value-weighted index. The Payout Yield is the sum of dividend yield and repurchase yield, defined as the ratio of common share repurchases to year-end market capitalization. We measure repurchases in two ways using the statement of cash flows (data from 1971) and the change in the treasury stock (data from 1983). Because repurchases were negligible prior to and just after the passing of SEC Rule 10b-18 in 1982, we assume that repurchases are zero before the availability of each measure. The Net Payout Yield is the sum of dividend yield and repurchase yield (using the statement of cash flows measure) less the issuance yield, defined as the ratio of common share issuances to year-end market capitalization. Since repurchase and issuance data from the statement of cash flows goes back only to 1971, we use the monthly change in shares outstanding from the CRSP monthly stock file to capture net equity issuances prior to 1971. In particular, net equity issuance for month $t$ is the product of the split-adjusted growth in shares and the average of the split adjusted stock-price at the beginning and end of the month. All variables are in $\operatorname{logs}(0.1$ is added to net payout yield to avoid negative yields). Panel A presents results from univariate regressions of log excess market return on dividend yield, payout yield(s), and net payout yield. Panel B presents the results from multivariate regressions of log excess market returns on dividend yield and either payout or net payout yield. All standard errors (SE) are heteroscedasticity-consistent. The t-statistics are the ratio of the coefficient to the standard error. The adjusted coefficient (Adj Coefficient) is computed using the method of Amihud and Hurvich (2004). Simulated P-values (Sim P-Value) are computed via 10,000 simulations under the null of zero predictability, but accounting for the regressor's autocorrelation and the cross correlation of the errors. The $R^{2}$ Sim P-Value is the corresponding $R^{2}$ from simulations under the null. The rho is the cross correlation between the errors of the $\mathrm{AR}(1)$ and the errors of the predictive regression. Adjusted beta and confidence interval are calculated following Amihud and Hurvich (2004). The Bonnferoni $Q$-test confidence interval is calculated following Campbell and Yogo (2005b). The Goyal Welch $(2003,2004)$ root-mean-squared error differential (dRMSE) uses 60 periods as the look back window and an out of sample period of 1985-2003. The Sim P-Value of the dRMSE measure is calculated within the simulations under the null described above. SE is the standard error. 
Panel A: Univariate Predictive Regressions

\begin{tabular}{|c|c|c|c|c|}
\hline & $\begin{array}{l}\text { Log(Dividend } \\
\text { Yield })\end{array}$ & $\begin{array}{l}\text { Log(Payout } \\
(\mathrm{CF}) \text { Yield) }\end{array}$ & $\begin{array}{l}\text { Log(Payout } \\
\text { (TS) Yield) }\end{array}$ & $\begin{array}{c}\log (0.1+\text { Net Payout } \\
\text { Yield }\end{array}$ \\
\hline \multicolumn{5}{|c|}{ Full Sample: 1926 - 2003} \\
\hline Coefficient & 0.116 & 0.209 & 0.172 & 0.759 \\
\hline SE & 0.052 & 0.062 & 0.060 & 0.143 \\
\hline t-statistic & 2.240 & 3.396 & 2.854 & 5.311 \\
\hline P-Value & 0.014 & 0.001 & 0.003 & 0.000 \\
\hline Sim Pval & 0.170 & 0.045 & 0.080 & 0.000 \\
\hline$R^{2}$ & 0.055 & 0.091 & 0.080 & 0.262 \\
\hline$R^{2}$ Sim Pval & 0.083 & 0.011 & 0.020 & 0.000 \\
\hline$\rho$ & -0.709 & -0.671 & -0.691 & -0.301 \\
\hline Adj. Coefficient & 0.072 & 0.167 & 0.126 & 0.736 \\
\hline SE & 0.056 & 0.076 & 0.067 & 0.146 \\
\hline t-statistic & 1.281 & 2.192 & 1.872 & 5.058 \\
\hline P-Value & 0.102 & 0.016 & 0.032 & 0.000 \\
\hline Bonferroni Q-Low & -0.007 & 0.035 & 0.014 & 0.313 \\
\hline Bonferroni Q-Hi & 0.151 & 0.267 & 0.209 & 0.641 \\
\hline dRMSE (GW) & -0.068 & 0.024 & -0.017 & 0.048 \\
\hline Sim Pval dRMSE & 0.932 & 0.082 & 0.703 & 0.022 \\
\hline \multicolumn{5}{|c|}{ Early Sample: 1926 - 1984} \\
\hline Coefficient & 0.296 & 0.280 & 0.300 & 0.794 \\
\hline $\mathrm{SE}$ & 0.081 & 0.076 & 0.080 & 0.149 \\
\hline t-statistic & 3.666 & 3.688 & 3.741 & 5.342 \\
\hline Bonferonni Q-Low & 0.070 & 0.065 & 0.077 & 0.347 \\
\hline Bonferonni Q-Hi & 0.389 & 0.387 & 0.390 & 0.735 \\
\hline P-Value & 0.000 & 0.000 & 0.000 & 0.000 \\
\hline Sim P-Value & 0.044 & 0.054 & 0.043 & 0.001 \\
\hline$R^{2}$ & 0.130 & 0.121 & 0.135 & 0.300 \\
\hline
\end{tabular}

Panel B: Multivariate Predictive Regressions

\begin{tabular}{lccccc}
\hline & $\begin{array}{c}\log (\text { Dividend } \\
\text { Yield })\end{array}$ & $\begin{array}{c}\log (\text { Payout } \\
(\mathrm{CF}) \text { Yield })\end{array}$ & $\begin{array}{c}\log (\text { Payout } \\
(\mathrm{TS}) \text { Yield })\end{array}$ & $\begin{array}{c}\log (0.1+\text { Net Payout } \\
\text { Yield }\end{array}$ & $R^{2}$ \\
\hline Coefficient & -0.088 & 0.318 & & & 0.098 \\
SE & 0.111 & 0.129 & & & 0.112 \\
\hline Coefficient & -0.394 & & 0.641 & & \\
SE & 0.216 & & 0.251 & & 0.267 \\
Coefficient & -0.042 & & & 0.830 & \\
SE & 0.064 & & & 0.108 & \\
\hline
\end{tabular}




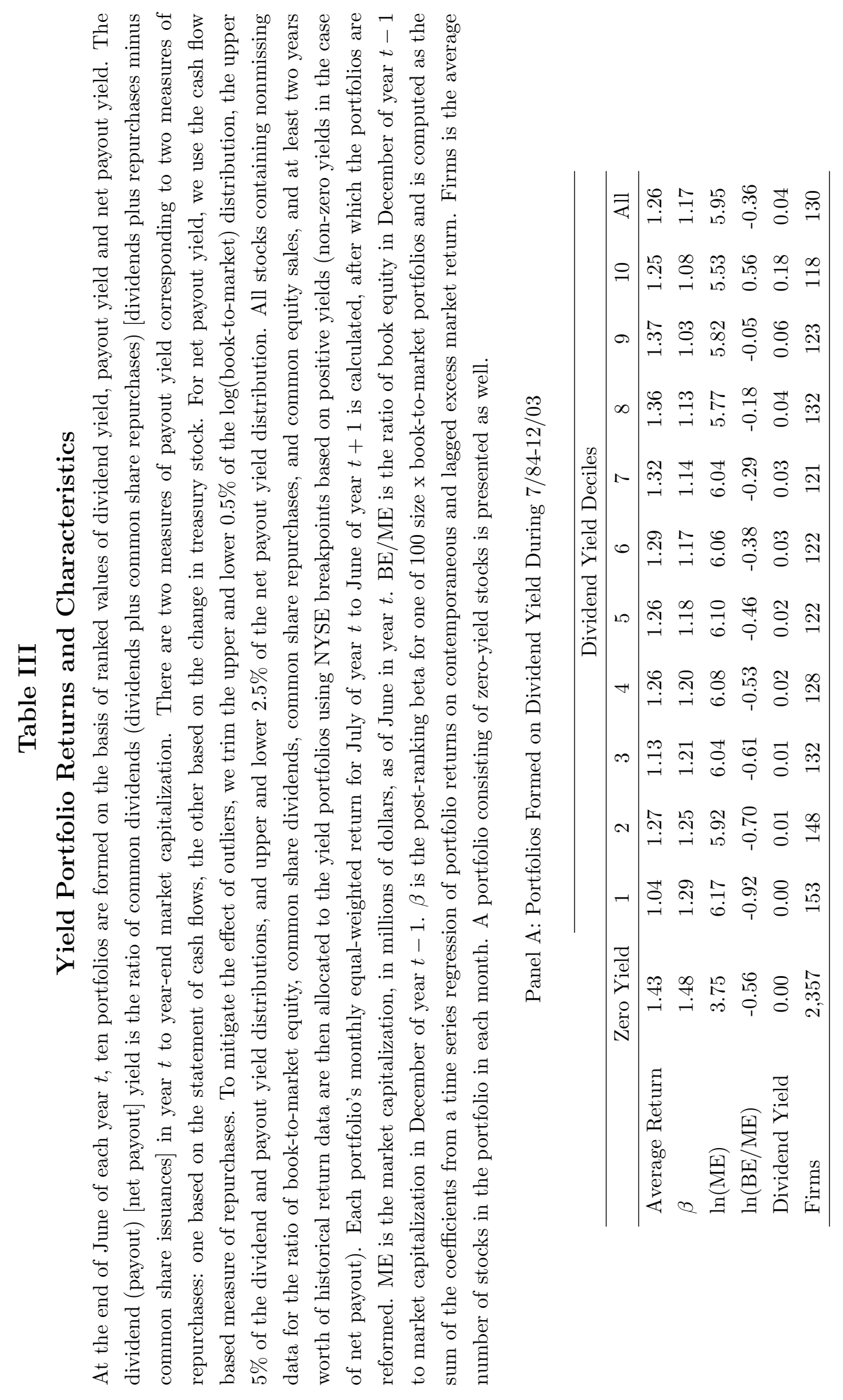




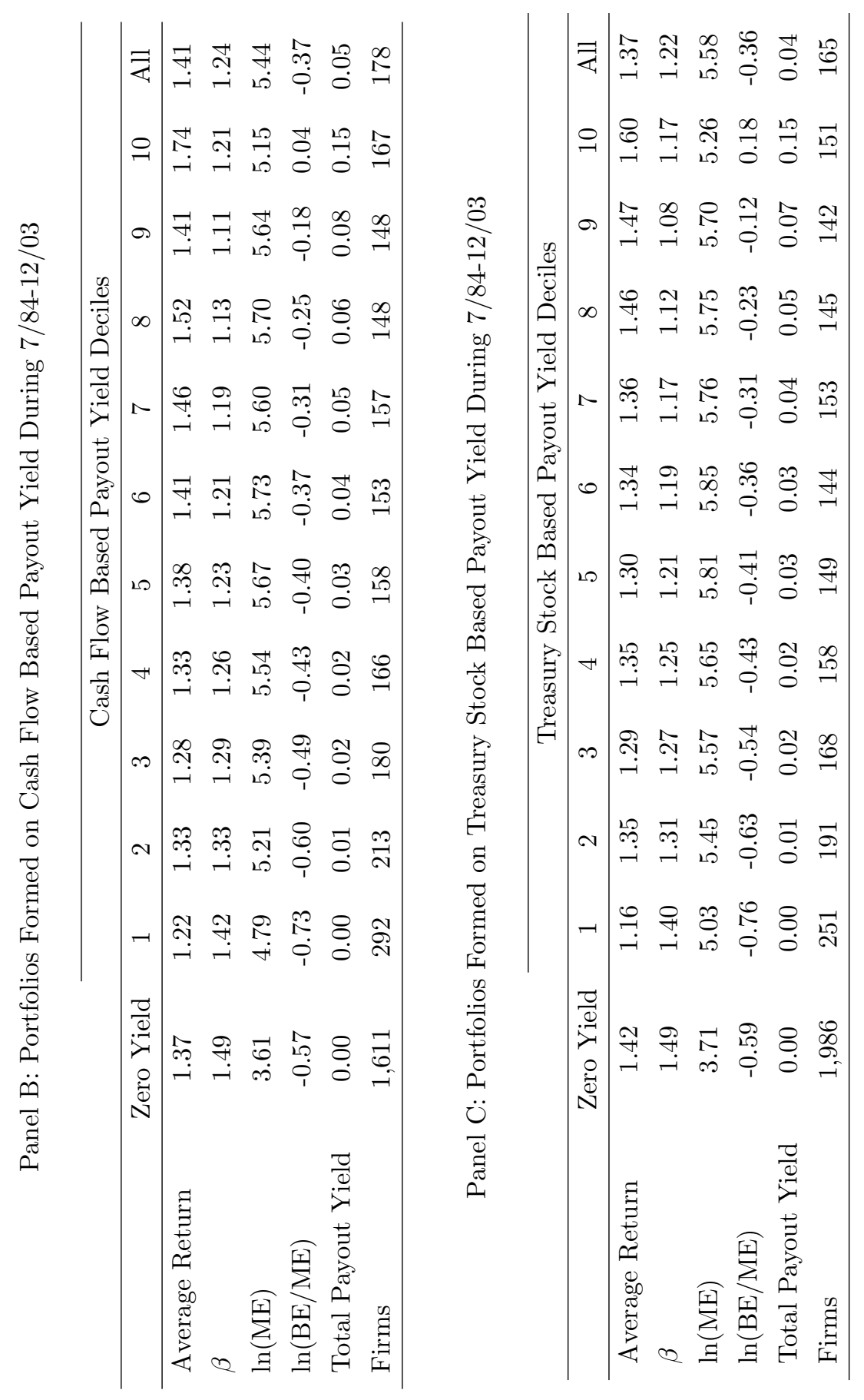




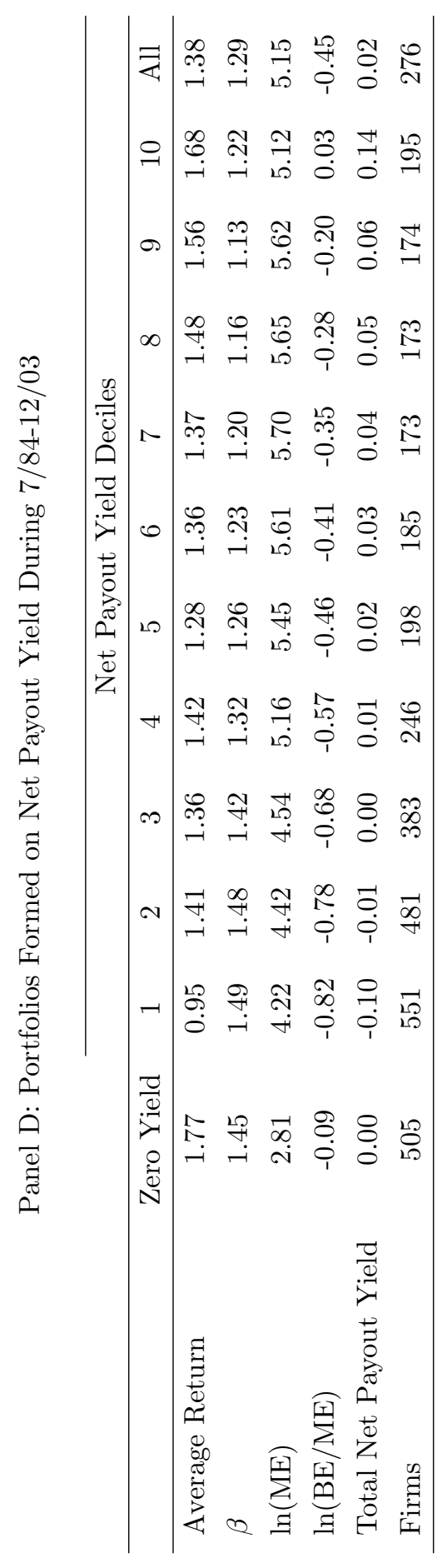




\section{Table IV}

\section{Fama-MacBeth Monthly Return Regressions}

The sample consists of all nonfinancial firms in the intersection of CRSP and Compustat with data for dividends paid to common shareholders, repurchase of common stock, and sale of common stock. The dividend (payout) [net payout] yield is the ratio of common dividends (dividends plus common share repurchases) [dividends plus repurchases minus common share issuances] in year $t$ to year-end market capitalization. There are two measures of payout yield corresponding to two measures of repurchases: one based on the statement of cash flows, the other based on the change in treasury stock. For net payout yield, we use the cash flow based measure of repurchases. To mitigate the effect of outliers, we trim the upper and lower $0.5 \%$ of the $\log$ (book-to-market) distribution, the upper $5 \%$ of the dividend and payout yield distributions, and upper and lower $2.5 \%$ of the net payout yield distribution. We also require that firms have at least two years worth of historical return data available on CRSP. Cross-sectional regressions are estimated each month. Mean is the time series mean of the estimated coefficients, Std is its time series standard deviation, and $\mathrm{t}(\mathrm{Mn})$ is Mean divided by its time series standard error. Market capitalization is denoted by ME, book equity is denoted by BE, common dividends is denoted by $\mathrm{D}$, cash flow based (treasury stock based) common share repurchases is denoted by RCF (RTS), and stock issuances is denoted by $\mathrm{S} . \beta$ is the post-ranking beta for one of 100 size $\mathrm{x}$ book-to-market portfolios and is computed as the sum of the coefficients from a time series regression of portfolio returns on contemporaneous and lagged excess market return. The table provides estimates based on ordinary least squares (OLS) and least absolute deviation (LAD) regressions. Panel A presents results for all nonmissing yield values, including zero yields. Zero dividend and repurchase yields are adjusted by adding 0.01 before converting to percentages and taking logs. Net payout yield is measured in percentages but not converted into logarithmic scale because of negative values. Panel B presents results for all positive yield values for dividend and payout, and all nonzero yields for net payout. 
Panel A: Entire Sample

\begin{tabular}{|c|c|c|c|c|c|c|}
\hline \multirow[b]{3}{*}{ Coefficient } & \multicolumn{3}{|c|}{ OLS Estimates } & \multicolumn{3}{|c|}{ LAD Estimates } \\
\hline & \multicolumn{3}{|c|}{ 7/84-12/03 (234 Mos.) } & \multicolumn{3}{|c|}{ 7/84-12/03 (234 Mos.) } \\
\hline & Mean & Std & $\mathrm{t}(\mathrm{Mn})$ & Mean & Std & $\mathrm{t}(\mathrm{Mn})$ \\
\hline \multicolumn{7}{|c|}{$R_{i t}=a+b_{1 t} \beta_{i t}+b_{2 t} \ln \left(M E_{i t}\right)+b_{3 t} \ln \left(B E_{i t} / M E_{i t}\right)+b_{4 t} \ln \left(D_{i t} / M E_{i t}\right)+e_{i t}$} \\
\hline Intercept & 2.33 & 7.27 & 4.90 & -0.81 & 6.47 & -1.91 \\
\hline$\beta$ & -0.03 & 6.06 & -0.07 & -0.46 & 5.52 & -1.26 \\
\hline $\ln (M E)$ & -0.16 & 1.08 & -2.34 & 0.30 & 0.81 & 5.72 \\
\hline $\ln (B E / M E)$ & 0.26 & 1.28 & 3.10 & 0.39 & 0.90 & 6.57 \\
\hline $\ln (D / M E)$ & 0.03 & 1.17 & 0.38 & 0.23 & 0.98 & 3.52 \\
\hline \multicolumn{7}{|c|}{$R_{i t}=a+b_{1 t} \beta_{i t}+b_{2 t} \ln \left(M E_{i t}\right)+b_{3 t} \ln \left(B E_{i t} / M E_{i t}\right)+b_{4 t} \ln \left((D+R C F)_{i t} / M E_{i t}\right)+e_{i t}$} \\
\hline Intercept & 2.11 & 7.07 & 4.56 & -1.01 & 6.23 & -2.49 \\
\hline$\beta$ & 0.05 & 5.92 & 0.12 & -0.35 & 5.43 & -0.98 \\
\hline $\ln (M E)$ & -0.16 & 1.04 & -2.37 & 0.29 & 0.78 & 5.77 \\
\hline $\ln (B E / M E)$ & 0.26 & 1.22 & 3.25 & 0.37 & 0.86 & 6.58 \\
\hline $\ln ((D+R C F) / M E)$ & 0.15 & 0.99 & 2.24 & 0.32 & 0.85 & 5.73 \\
\hline \multicolumn{7}{|c|}{$R_{i t}=a+b_{1 t} \beta_{i t}+b_{2 t} \ln \left(M E_{i t}\right)+b_{3 t} \ln \left(B E_{i t} / M E_{i t}\right)+b_{4 t} \ln \left((D+R T S)_{i t} / M E_{i t}\right)+e_{i t}$} \\
\hline Intercept & 2.24 & 7.18 & 4.77 & -0.91 & 6.37 & -2.20 \\
\hline$\beta$ & 0.02 & 5.99 & 0.06 & -0.41 & 5.50 & -1.14 \\
\hline $\ln (M E)$ & -0.17 & 1.07 & -2.43 & 0.30 & 0.80 & 5.74 \\
\hline $\ln (B E / M E)$ & 0.24 & 1.28 & 2.92 & 0.38 & 0.92 & 6.36 \\
\hline $\ln ((D+R T S) / M E)$ & 0.11 & 1.11 & 1.50 & 0.27 & 0.94 & 4.43 \\
\hline \multicolumn{7}{|c|}{$R_{i t}=a+b_{1 t} \beta_{i t}+b_{2 t} \ln \left(M E_{i t}\right)+b_{3 t} \ln \left(B E_{i t} / M E_{i t}\right)+b_{4 t}(D+R C F-S)_{i t} / M E_{i t}+e_{i t}$} \\
\hline Intercept & 2.11 & 7.10 & 4.55 & -0.73 & 6.45 & -1.74 \\
\hline$\beta$ & 0.10 & 6.12 & 0.26 & -0.40 & 5.59 & -1.10 \\
\hline $\ln (M E)$ & -0.15 & 1.03 & -2.22 & 0.31 & 0.76 & 6.17 \\
\hline $\ln (B E / M E)$ & 0.27 & 1.25 & 3.29 & 0.39 & 0.92 & 6.52 \\
\hline$(D+R C F-S) / M E$ & 0.03 & 0.10 & 4.14 & 0.04 & 0.08 & 8.09 \\
\hline
\end{tabular}


Panel B: Positive Yield Subsample

\begin{tabular}{|c|c|c|c|c|c|c|}
\hline \multirow[b]{3}{*}{ Coefficient } & \multicolumn{3}{|c|}{ OLS Estimates } & \multicolumn{3}{|c|}{ LAD Estimates } \\
\hline & \multicolumn{3}{|c|}{ 7/84-12/03 (234 Mos.) } & \multicolumn{3}{|c|}{ 7/84-12/03 (234 Mos.) } \\
\hline & Mean & Std & $\mathrm{t}(\mathrm{Mn})$ & Mean & Std & $\mathrm{t}(\mathrm{Mn})$ \\
\hline \multicolumn{7}{|c|}{$R_{i t}=a+b_{1 t} \beta_{i t}+b_{2 t} \ln \left(M E_{i t}\right)+b_{3 t} \ln \left(B E_{i t} / M E_{i t}\right)+b_{4 t} \ln \left(D_{i t} / M E_{i t}\right)+e_{i t}$} \\
\hline Intercept & 1.47 & 6.60 & 3.41 & 0.25 & 6.41 & 0.59 \\
\hline$\beta$ & -0.08 & 5.29 & -0.23 & -0.30 & 5.02 & -0.92 \\
\hline $\ln (M E)$ & -0.02 & 0.72 & -0.33 & 0.13 & 0.69 & 2.88 \\
\hline $\ln (B E / M E)$ & 0.08 & 0.91 & 1.31 & -0.00 & 0.86 & -0.01 \\
\hline $\ln (D / M E)$ & 0.02 & 0.63 & 0.43 & 0.07 & 0.63 & 1.58 \\
\hline \multicolumn{7}{|c|}{$R_{i t}=a+b_{1 t} \beta_{i t}+b_{2 t} \ln \left(M E_{i t}\right)+b_{3 t} \ln \left(B E_{i t} / M E_{i t}\right)+b_{4 t} \ln \left((D+R C F)_{i t} / M E_{i t}\right)+e_{i t}$} \\
\hline Intercept & 1.73 & 6.39 & 4.15 & -0.26 & 6.26 & -0.63 \\
\hline$\beta$ & 0.08 & 5.81 & 0.21 & -0.26 & 5.35 & -0.76 \\
\hline $\ln (M E)$ & -0.08 & 0.85 & -1.40 & 0.20 & 0.71 & 4.22 \\
\hline $\ln (B E / M E)$ & 0.18 & 1.10 & 2.49 & 0.14 & 0.83 & 2.63 \\
\hline $\ln ((D+R C F) / M E)$ & 0.06 & 0.48 & 1.94 & 0.12 & 0.46 & 3.99 \\
\hline \multicolumn{7}{|c|}{$R_{i t}=a+b_{1 t} \beta_{i t}+b_{2 t} \ln \left(M E_{i t}\right)+b_{3 t} \ln \left(B E_{i t} / M E_{i t}\right)+b_{4 t} \ln \left((D+R T S)_{i t} / M E_{i t}\right)+e_{i t}$} \\
\hline Intercept & 1.78 & 6.23 & 4.37 & -0.11 & 6.07 & -0.29 \\
\hline$\beta$ & 0.04 & 5.51 & 0.11 & -0.29 & 5.09 & -0.88 \\
\hline $\ln (M E)$ & -0.08 & 0.84 & -1.38 & 0.18 & 0.71 & 3.89 \\
\hline $\ln (B E / M E)$ & 0.15 & 1.03 & 2.18 & 0.10 & 0.82 & 1.86 \\
\hline $\ln ((D+R T S) / M E)$ & 0.05 & 0.51 & 1.45 & 0.11 & 0.45 & 3.56 \\
\hline \multicolumn{7}{|c|}{$R_{i t}=a+b_{1 t} \beta_{i t}+b_{2 t} \ln \left(M E_{i t}\right)+b_{3 t} \ln \left(B E_{i t} / M E_{i t}\right)+b_{4 t}(D+R C F-S)_{i t} / M E_{i t}+e_{i t}$} \\
\hline Intercept & 1.77 & 7.20 & 3.76 & -0.77 & 6.68 & -1.76 \\
\hline$\beta$ & 0.21 & 6.27 & 0.50 & -0.27 & 5.71 & -0.73 \\
\hline $\ln (M E)$ & -0.11 & 1.00 & -1.62 & 0.29 & 0.76 & 5.85 \\
\hline $\ln (B E / M E)$ & 0.28 & 1.32 & 3.21 & 0.39 & 0.99 & 6.02 \\
\hline$(D+R C F-S) / M E$ & 0.03 & 0.10 & 4.03 & 0.04 & 0.08 & 8.64 \\
\hline
\end{tabular}




\section{Table V \\ Factor Regressions}

The sample consists of all nonfinancial firms in the intersection of CRSP and Compustat with data for dividends paid to common shareholders, repurchase of common stock, and sale of common stock. The dividend (payout) [net payout] yield is the ratio of common dividends (dividends plus common share repurchases) [dividends plus repurchases minus common share issuances] in year $t$ to year-end market capitalization. To mitigate the effect of outliers, we trim the upper $5 \%$ of the dividend and payout yield distributions, and upper and lower $2.5 \%$ of the net payout yield distribution. We also require that firms have at least two years worth of historical return data available on CRSP. The regression equation is:

$$
R_{t}-R f_{t}=\alpha+\beta_{1}\left[R M_{t}-R f_{t}\right]+\beta_{2} S M B_{t}+\beta_{3} H M L_{t}+\beta_{4} Y I E L D H M L_{t}+\varepsilon_{t} .
$$

The regressand is monthly excess portfolio returns, $R_{t}-R f_{t}$, from $7 / 1984$ to $12 / 2003$, and the regressors are the market excess return $\left(R M_{t}-R f_{t}\right)$, the small minus big factor return $\left(S M B_{t}\right)$, the high minus low factor return $\left(H M L_{t}\right)$, and the high minus low yield factor return for the dividend yields, payout yields, and net payout yields. The first three regressors are obtained from Ken French's website. YIELDHML corresponds to one of four yield factors: dividend (DYHML), cash flow based payout (PYCFHML), treasury stock based payout (PYTSHML), or net payout (NPYHML). The table presents intercept and yield factor slope coefficient estimates (and corresponding t-statistics) for 25 portfolios formed on book-to-market and payout yield (panel A). Panel B presents a summary of statistical tests of intercept significance for five different model specifications and the three aforementioned sets of portfolios. $\chi^{2}$ is the test-statistics corresponding to a Wald test of the joint hypothesis that all of the intercepts are equal to 0 . One asterisk (two asterisk) correspond to statistical significance at the $5 \%$ (1\%) level. 
Panel A: Book-to-Market Equity/Payout Yield Portfolios

\begin{tabular}{|c|c|c|c|c|c|c|c|c|c|c|}
\hline & \multicolumn{10}{|c|}{ Payout Yield Quintiles } \\
\hline & Low & \multirow{2}{*}{2} & \multirow{2}{*}{3} & \multirow{2}{*}{4} & High & Low & 2 & 3 & \multirow{2}{*}{4} & High \\
\hline & Yield & & & & Yield & Yield & 2 & 3 & & Yield \\
\hline \multirow[t]{2}{*}{ B/M Quintiles } & \multicolumn{10}{|c|}{$Y I E L D H M L=$ Dividend Yield } \\
\hline & \multicolumn{5}{|c|}{$\alpha$} & \multicolumn{5}{|c|}{$\mathrm{t}(\alpha)$} \\
\hline Small & 0.04 & -0.02 & 0.30 & 0.55 & 0.53 & 0.33 & -0.16 & 2.11 & 3.04 & 2.45 \\
\hline 2 & -0.15 & -0.12 & 0.09 & 0.05 & 0.16 & -1.12 & -0.75 & 0.51 & 0.26 & 0.77 \\
\hline 3 & -0.32 & -0.33 & -0.15 & 0.11 & 0.16 & -1.82 & -1.78 & -0.79 & 0.61 & 0.82 \\
\hline 4 & -0.36 & -0.09 & 0.03 & -0.28 & 0.02 & -2.07 & -0.43 & 0.16 & -1.81 & 0.13 \\
\hline \multirow[t]{2}{*}{ Big } & -0.37 & -0.41 & -0.36 & -0.26 & 0.11 & -1.94 & -1.69 & -1.37 & -1.42 & 0.69 \\
\hline & \multicolumn{5}{|c|}{$\beta_{4}$} & \multicolumn{5}{|c|}{$\mathrm{t}\left(\beta_{4}\right)$} \\
\hline Small & -0.24 & -0.16 & -0.15 & 0.01 & -0.30 & -5.07 & -2.81 & -2.71 & 0.15 & -3.62 \\
\hline 2 & -0.14 & -0.20 & -0.06 & 0.06 & -0.09 & -2.71 & -3.11 & -0.86 & 0.91 & -1.05 \\
\hline 3 & -0.24 & -0.10 & 0.14 & 0.31 & 0.11 & -3.49 & -1.34 & 1.97 & 4.44 & 1.48 \\
\hline 4 & -0.10 & -0.18 & -0.01 & 0.36 & 0.23 & -1.57 & -2.24 & -0.16 & 5.92 & 3.41 \\
\hline \multirow[t]{3}{*}{ Big } & -0.02 & -0.17 & 0.00 & 0.21 & 0.30 & -0.30 & -1.82 & 0.03 & 2.91 & 5.19 \\
\hline & \multicolumn{10}{|c|}{ YIELDHML $=$ Cash Flow Based Payout Yield } \\
\hline & \multicolumn{5}{|c|}{$\alpha$} & \multicolumn{5}{|c|}{$\mathrm{t}(\alpha)$} \\
\hline Small & 0.17 & 0.06 & 0.33 & 0.43 & 0.33 & 1.34 & 0.38 & 2.25 & 2.37 & 1.53 \\
\hline 2 & -0.15 & -0.12 & 0.17 & 0.01 & -0.03 & -1.04 & -0.67 & 0.94 & 0.05 & -0.17 \\
\hline 3 & -0.24 & -0.28 & -0.14 & 0.04 & 0.05 & -1.28 & -1.45 & -0.75 & 0.21 & 0.27 \\
\hline 4 & -0.31 & 0.00 & 0.04 & -0.31 & -0.13 & -1.78 & 0.01 & 0.17 & -1.82 & -0.73 \\
\hline \multirow[t]{2}{*}{ Big } & -0.28 & -0.26 & -0.27 & -0.32 & 0.01 & -1.45 & -1.06 & -1.03 & -1.66 & 0.05 \\
\hline & \multicolumn{5}{|c|}{$\beta_{4}$} & \multicolumn{5}{|c|}{$\mathrm{t}\left(\beta_{4}\right)$} \\
\hline Small & -0.26 & -0.17 & -0.06 & 0.26 & 0.42 & -5.18 & -2.77 & -1.02 & 3.64 & 4.95 \\
\hline 2 & -0.01 & -0.01 & -0.16 & 0.07 & 0.41 & -0.13 & -0.18 & -2.25 & 1.03 & 5.09 \\
\hline 3 & -0.18 & -0.12 & -0.01 & 0.14 & 0.22 & -2.44 & -1.56 & -0.15 & 1.81 & 2.79 \\
\hline 4 & -0.09 & -0.18 & -0.01 & 0.05 & 0.31 & -1.27 & -2.21 & -0.11 & 0.71 & 4.42 \\
\hline Big & -0.19 & -0.32 & -0.18 & 0.11 & 0.19 & -2.54 & -3.26 & -1.67 & 1.40 & 3.03 \\
\hline
\end{tabular}


Panel A: (Cont.) Book-to-Market Equity/Payout Yield Portfolios

Payout Yield Quintiles

\begin{tabular}{|c|c|c|c|c|c|c|c|c|c|c|}
\hline & \multicolumn{10}{|c|}{ Payout Yield Quintiles } \\
\hline & $\begin{array}{l}\text { Low } \\
\text { Yield }\end{array}$ & 2 & 3 & 4 & $\begin{array}{l}\text { High } \\
\text { Yield }\end{array}$ & $\begin{array}{l}\text { Low } \\
\text { Yield }\end{array}$ & 2 & 3 & 4 & $\begin{array}{l}\text { High } \\
\text { Yield }\end{array}$ \\
\hline B/M Quintiles & \multicolumn{10}{|c|}{$Y I E L D H M L=$ Treasury Stock Based Payout Yield } \\
\hline & \multicolumn{5}{|c|}{$\alpha$} & \multicolumn{5}{|c|}{$\mathrm{t}(\alpha)$} \\
\hline Small & 0.11 & 0.02 & 0.32 & 0.51 & 0.49 & 0.86 & 0.13 & 2.23 & 2.83 & 2.24 \\
\hline 2 & -0.13 & -0.11 & 0.12 & 0.04 & 0.13 & -0.93 & -0.65 & 0.68 & 0.21 & 0.61 \\
\hline 3 & -0.28 & -0.33 & -0.16 & 0.05 & 0.13 & -1.52 & -1.77 & -0.85 & 0.27 & 0.66 \\
\hline 4 & -0.35 & -0.08 & 0.05 & -0.30 & -0.04 & -2.03 & -0.37 & 0.22 & -1.81 & -0.25 \\
\hline \multirow{2}{*}{ Big } & -0.33 & -0.37 & -0.37 & -0.29 & 0.02 & -1.74 & -1.50 & -1.39 & -1.51 & 0.13 \\
\hline & \multicolumn{5}{|c|}{$\beta_{4}$} & \multicolumn{5}{|c|}{$\mathrm{t}\left(\beta_{4}\right)$} \\
\hline Small & -0.19 & -0.12 & -0.06 & 0.12 & 0.10 & -4.68 & -2.60 & -1.32 & 2.05 & 1.43 \\
\hline 2 & -0.07 & -0.03 & -0.09 & 0.02 & 0.10 & -1.49 & -0.62 & -1.55 & 0.41 & 1.50 \\
\hline 3 & -0.13 & 0.01 & 0.03 & 0.16 & 0.08 & -2.22 & 0.10 & 0.55 & 2.71 & 1.26 \\
\hline 4 & -0.01 & -0.02 & -0.04 & 0.05 & 0.19 & -0.13 & -0.36 & -0.64 & 0.96 & 3.34 \\
\hline \multirow[t]{3}{*}{ Big } & -0.11 & -0.13 & 0.02 & 0.06 & 0.24 & -1.84 & -1.60 & 0.24 & 0.93 & 4.87 \\
\hline & \multicolumn{10}{|c|}{$Y I E L D H M L=$ Net Payout Yield } \\
\hline & \multicolumn{5}{|c|}{$\alpha$} & \multicolumn{5}{|c|}{$\mathrm{t}(\alpha)$} \\
\hline Small & 0.20 & -0.11 & 0.24 & 0.24 & 0.32 & 1.54 & -0.74 & 1.63 & 1.45 & 1.45 \\
\hline 2 & -0.08 & -0.19 & 0.02 & -0.07 & -0.08 & -0.55 & -1.08 & 0.09 & -0.40 & -0.38 \\
\hline 3 & -0.25 & -0.28 & -0.06 & -0.04 & 0.02 & -1.33 & -1.44 & -0.31 & -0.22 & 0.08 \\
\hline 4 & -0.28 & -0.16 & 0.04 & -0.33 & -0.14 & -1.59 & -0.75 & 0.17 & -1.94 & -0.76 \\
\hline Big & -0.25 & -0.36 & -0.25 & -0.26 & 0.03 & -1.28 & -1.41 & -0.94 & -1.32 & 0.16 \\
\hline & \multicolumn{5}{|c|}{$\beta_{4}$} & \multicolumn{5}{|c|}{$\mathrm{t}\left(\beta_{4}\right)$} \\
\hline Small & -0.26 & 0.16 & 0.10 & 0.55 & 0.37 & -5.22 & 2.58 & 1.81 & 8.46 & 4.24 \\
\hline 2 & -0.13 & 0.11 & 0.13 & 0.20 & 0.42 & -2.28 & 1.61 & 1.81 & 2.86 & 5.16 \\
\hline 3 & -0.13 & -0.10 & -0.15 & 0.26 & 0.25 & -1.71 & -1.25 & -2.05 & 3.42 & 3.13 \\
\hline 4 & -0.13 & 0.13 & -0.01 & 0.08 & 0.27 & -1.82 & 1.51 & -0.09 & 1.16 & 3.80 \\
\hline Big & -0.21 & -0.10 & -0.18 & -0.02 & 0.13 & -2.82 & -0.96 & -1.73 & -0.24 & 2.00 \\
\hline
\end{tabular}




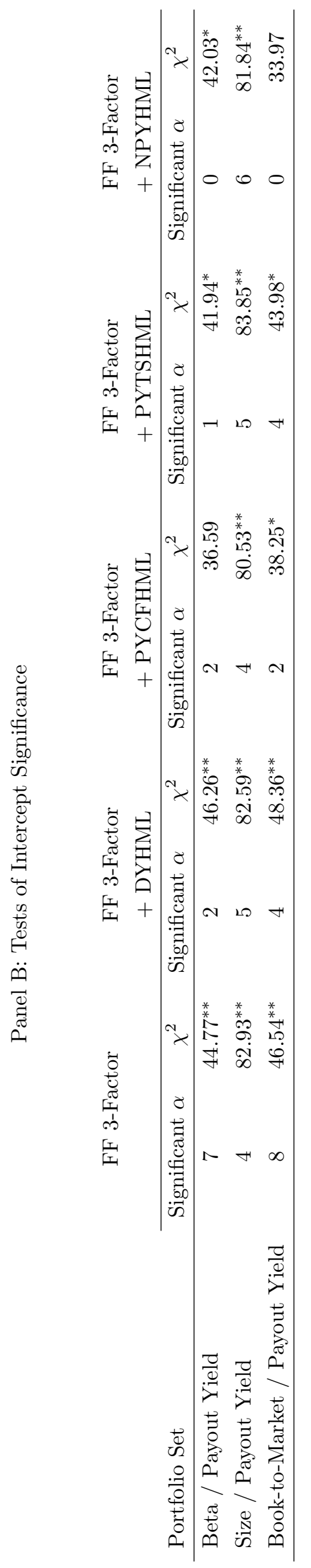




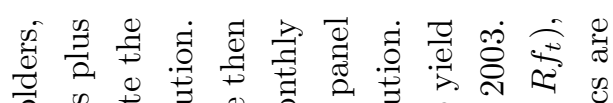

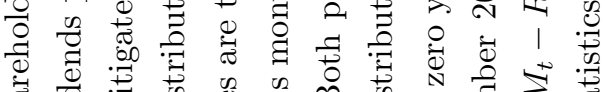

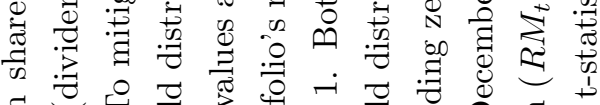

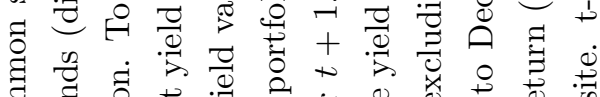

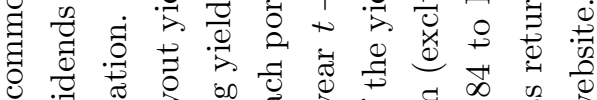
8.

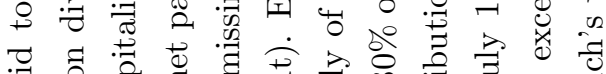

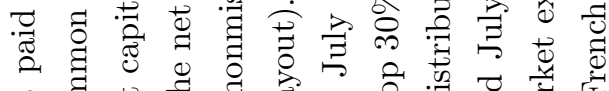

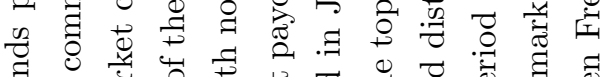

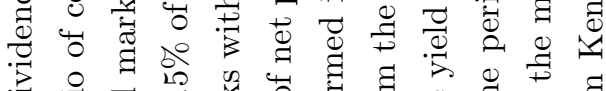

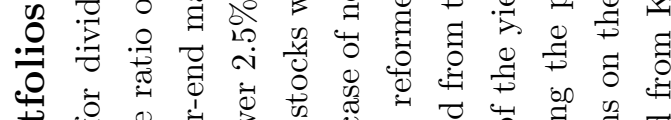

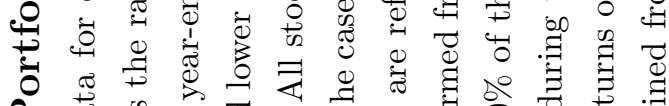

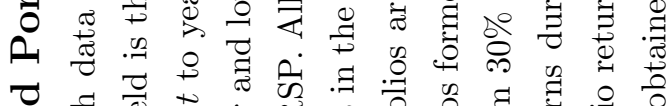

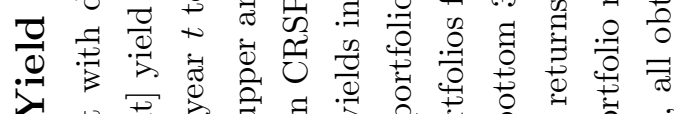

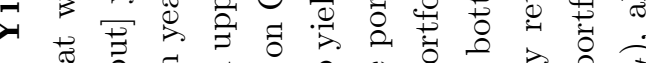

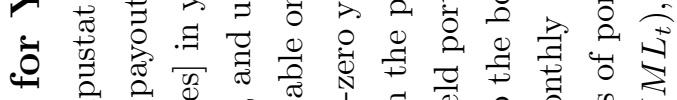

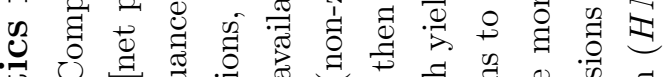

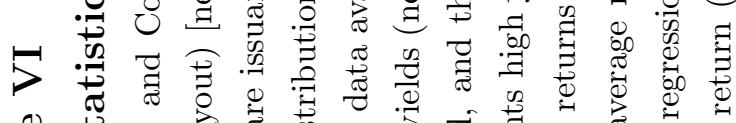

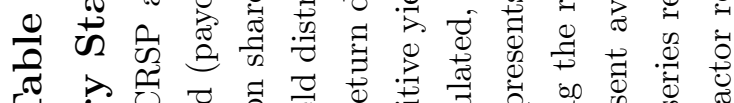

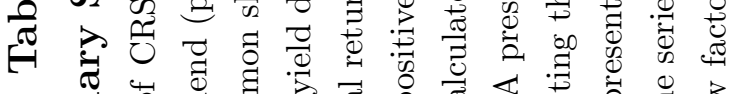
可

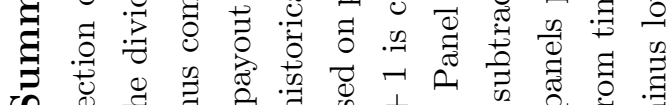

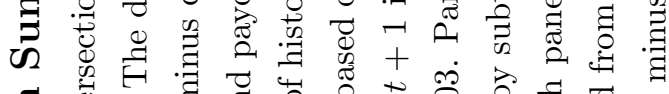

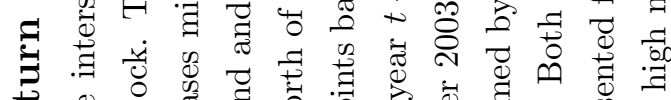

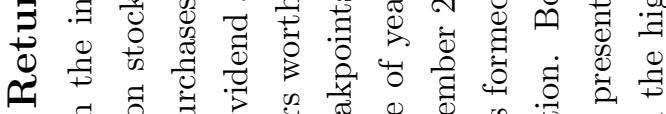

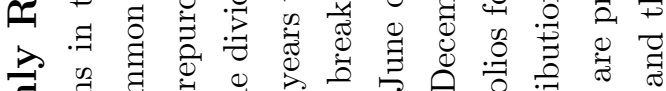

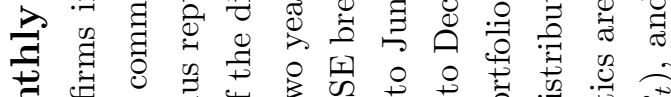
要者

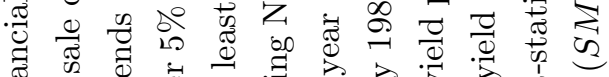

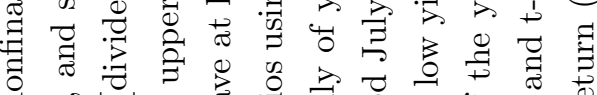
等

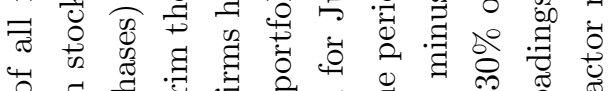

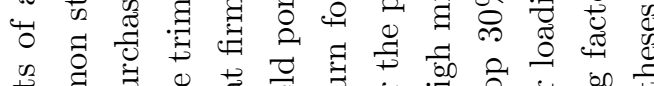

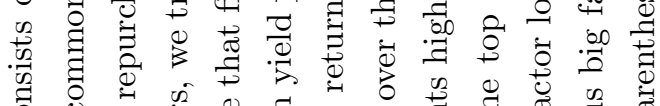

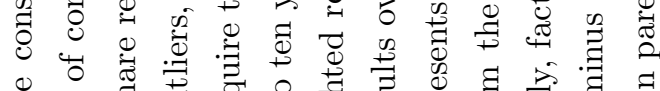

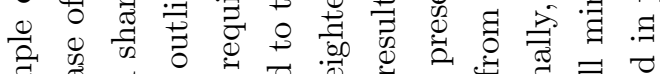

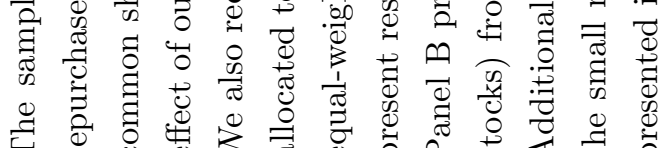

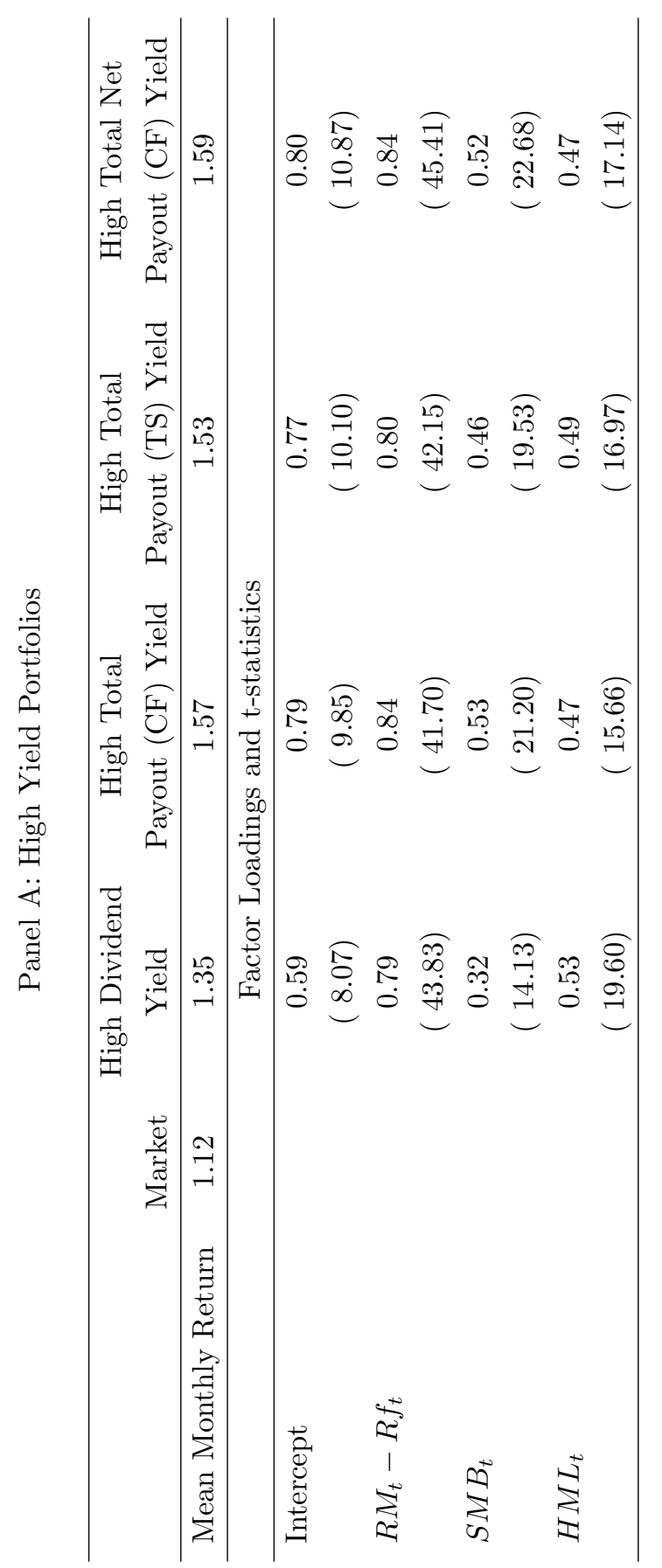




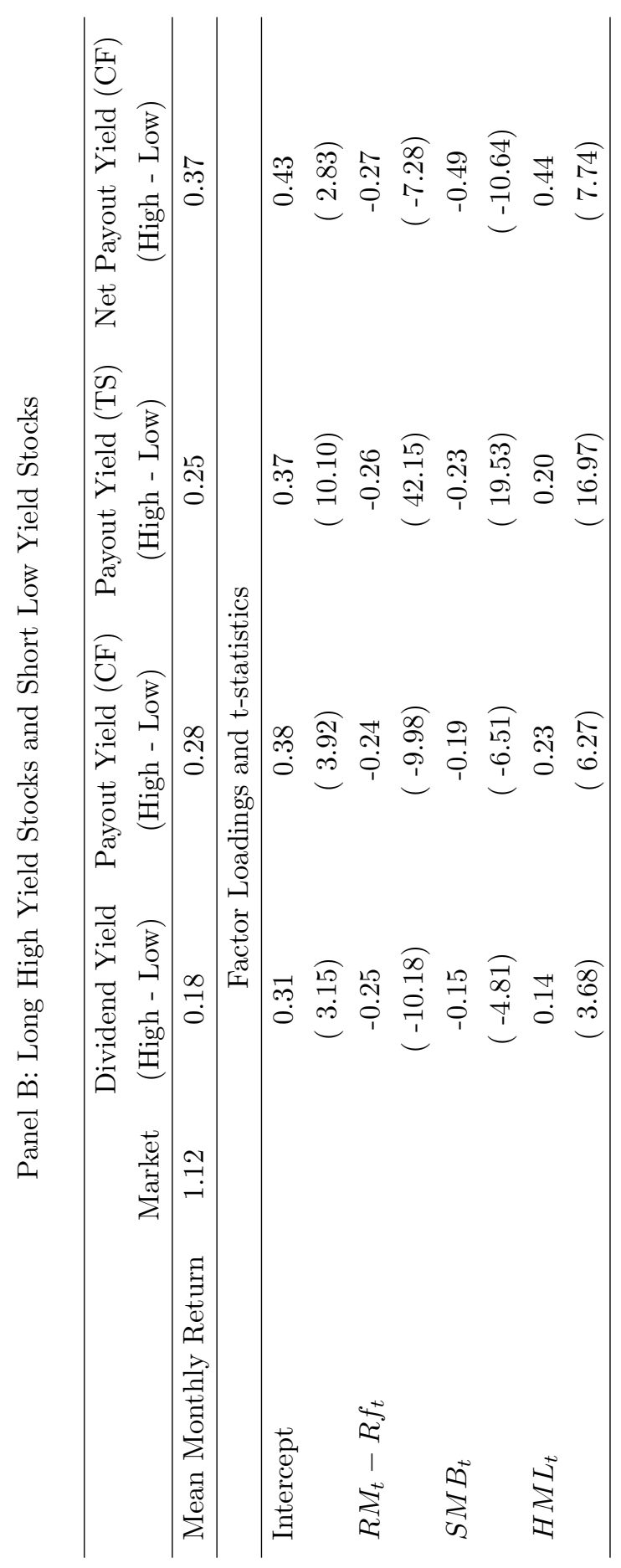

